\title{
Effects of group-housing on sow welfare
}

\section{a review}

Verdon, M.; Hansen, Christian Fink; Rault, J.-L.; Jongman, E.; Hansen, L. U.; Plush, K.; Hemsworth, P. H.

Published in:

Journal of Animal Science

DOI:

$10.2527 / j a s .2014-8742$

Publication date:

2015

Document version

Early version, also known as pre-print

Citation for published version (APA):

Verdon, M., Hansen, C. F., Rault, J-L., Jongman, E., Hansen, L. U., Plush, K., \& Hemsworth, P. H. (2015). Effects of group-housing on sow welfare: a review. Journal of Animal Science, 93(5), 1999-2017. https://doi.org/10.2527/jas.2014-8742 


\title{
Effects of group housing on sow welfare: A review ${ }^{1}$
}

\author{
M. Verdon, * C. F. Hansen, † J.-L. Rault,* E. Jongman,* L. U. Hansen, $\ddagger$ K. Plush, § and P. H. Hemsworth*2 \\ *Animal Welfare Science Centre, Faculty of Veterinary and Agricultural Sciences, University of Melbourne, VIC, 3010 , \\ Australia; †Department of Large Animal Sciences, Faculty of Health and Medical Sciences, University of Copenhagen, \\ DK-1870 Frederiksberg C, Denmark; \$Pig Research Centre, Danish Agriculture and Food Council, Copenhagen, 1609 \\ Copenhagen V, Denmark; and §School of Animal and Veterinary Science, University of Adelaide, SA, 5371, Australia
}

\begin{abstract}
Factors that have been shown to impact the welfare of group-housed sows are discussed in this review. Floor space allowance markedly affects sow welfare. In addition to quantity of floor space, the quality of space is important: spatial separation between sows can be provided with visual or physical barriers and stalls. Whereas $1.4 \mathrm{~m}^{2} /$ sow is insufficient, further research is required to examine space effects in the range of 1.8 to $2.4 \mathrm{~m}^{2} / \mathrm{sow}$ in more detail. The period immediately after mixing has the most pronounced effects on aggression and stress, and therefore, welldesigned mixing pens offer the opportunity to reduce aggression, injury, and stress while allowing the social hierarchy to quickly form. Because hunger is likely to lead to competition for feed or access to feeding areas, strategies to reduce hunger between meals through higher feeding levels, dietary fiber, or foraging substrate should be examined. However, feeding systems,
\end{abstract}

such as full-body feeding stalls, can also affect aggression and stress by providing protection at feeding, but deriving conclusions on this topic is difficult because research directly comparing floor feeding, feeding stalls, and electronic sow feeder systems has not been conducted. Familiar sows engage in less aggression, so mixing sows that have been housed together in the previous gestation may reduce aggression. Although there is evidence in other species that early experience may affect social skills later in life, there are few studies on the effects of early "socialization" on aggressive behavior of adult sows. Genetic selection has the potential to reduce aggression, and therefore, continued research on the opportunity to genetically select against aggressiveness and its broader implications is required. Most research to date has examined mixing sows after insemination and knowledge on grouping after weaning is limited.

Key words: aggression, group housing, productivity, sow, welfare

(C) 2015 American Society of Animal Science. All rights reserved. J. Anim. Sci. 2015.93:1999-2017 doi:10.2527/jas2014-8742

\section{INTRODUCTION}

With legislative, consumer, and retailer pressure on the housing of sows in gestation stalls (Matthews and Hemsworth, 2012), many countries have moved to, or are moving to, group-housing systems for most of gestation. However, high levels of aggression are common in

\footnotetext{
${ }^{1}$ This work was partially funded by a grant from the Australian Pork Cooperative Research Centre. We thank the University of Melbourne, University of Copenhagen, and the Pig Research Centre, Denmark, for support and intellectual input.

${ }^{2}$ Corresponding author: phh@unimelb.edu.au

Received November 19, 2014.

Accepted March 7, 2015.
}

newly formed groups of sows (Velarde, 2007). This aggression may adversely affect sow welfare, particularly because of its effect on fear, injuries, pain, and stress.

There is complexity and wide disparity in the design and management of commercial group-housing systems, although many of these features can affect sow welfare. For example, housing features, such as space allowance, group size, static and dynamic groups, and use of a mixing pen, and sow nutrition, including diet, ration, and feeding system, may affect sow welfare. Also, sow welfare may be influenced by animal characteristics, such as genetics, experience, stage of reproduction, and parity, as well as by "stockmanship."

Although recent reviews by Bench et al. (2013a,b) provide detailed recommendations on the management 
of grouped sows that are individually fed, most recommendations on design features that affect sow welfare are more general, such as for increased floor space allowance and the provision of feeding stalls (Barnett et al., 2001; Spoolder et al., 2009). Furthermore, current research on design features is based mostly on grouping after insemination or confirmation of pregnancy, and few studies have examined the effects of grouping after weaning on sow welfare (Rault et al., 2014). By contrast, considerable research has examined the effects of grouping on juvenile pigs. Although some of this research is applicable to sows, caution is required because of differences in age, experience, physiological state, and housing and feeding systems. This review adds to recent reviews by Bench et al. (2013a,b) by considering the main factors of group housing, from weaning and after insemination, that may affect sow aggression, injuries, and stress.

\section{ASSESSMENT OF SOW WELFARE}

The assessment of animal welfare uses multiple indicators from multiple disciplines, but quantification of the relative importance of these indicators is lacking (Barnett et al., 2001; Fraser, 2008; Nicol et al., 2011). A review of the scientific approaches used in assessing animal welfare and their rationale can be viewed elsewhere (e.g., Barnett and Hemsworth, 2009). Research on the effects of group housing has predominantly used aggression, injuries, and physiological stress to assess the welfare of sows. Specifically, aggression has obvious welfare implications because of its consequences on injuries and stress (Mendl et al., 1992; Nicholson et al., 1993) and their probable links to pain and fear. Skin injuries are often used as proxy measures for aggression (e.g., Turner et al., 2006; Schneider et al., 2007). However, changes in aggression per se do not always correspond to changes in skin injuries because animals can be injured in other ways, such as by slipping or colliding with features of the pen while fighting or avoiding other sows (e.g., Hemsworth et al., 2013). Therefore, this review is primarily based on measures of aggression, injuries, and stress when examining the welfare of sows in groups.

\section{FACTORS AFFECTING WELFARE IN THE GROUPED SOW}

\section{Housing}

Floor Space Allowance. Insufficient floor space, both in quantity (amount) and quality (configuration, including physical and visual barriers), can prolong aggression by affecting a sow's ability to avoid or escape others and hence the formation of a stable hierarchy (Lindberg, 2001). A summary of the literature regarding the effect of increasing floor space allowance on a range of welfare variables can be seen in Table 1 .

From the few studies that have been conducted, increased space allowance (see Table 1 for specifics) does not reduce aggressive behavior for up to $2 \mathrm{~h}$ immediately after mixing (Barnett et al., 1992; Barnett, 1997; Remience et al., 2008). However, at d 2 to 54 after mixing, increasing space reduced aggressive behaviors, such as bites and butts, between pregnant gilts (Barnett et al., 1992; Barnett, 1997). Similarly for sows, the number of threats, withdrawals, and head interactions, including bites and nose interactions, were reduced with increasing space at d 6 and 7 after mixing (Weng et al., 1998). Furthermore, although reciprocal aggressive behavior (bites or knocks) did not differ, Remience et al. (2008) found that nonreciprocal aggression at $\mathrm{d} 3$ and 8 after mixing was greater in pregnant sows at a smaller floor space. For sows mixed soon after insemination, increasing space reduced feeding aggression at $\mathrm{d} 2$ after mixing but not at d 8 (Hemsworth et al., 2013). Therefore, it appears that the effect of floor space on aggression is particularly pronounced early after mixing. Although the formation of a social hierarchy may assist in reducing aggression over time (Gonyou, 2001), static groups may also adapt to reduced space (Hemsworth et al., 2013). However, there is little evidence in the literature regarding habituation to spatial restrictions in groups, and therefore, the mechanisms involved and the role of pregnancy in this remain unclear (see Hemsworth et al., 2013).

Increasing space reduced basal concentrations of plasma cortisol of gilts at $\mathrm{d} 2$ to 54 (Barnett et al., 1992; Barnett, 1997) and at d 9 to 11 and d 67 to 76 of treatment (Hemsworth et al., 1986a). In a study of 3,120 sows, Hemsworth et al. (2013) found that increasing floor space corresponded to a linear reduction in plasma cortisol concentrations at $\mathrm{d} 2$ after mixing. However, the authors concluded that this reduction could be interpreted as either a linear decline or a plateau, declining from 1.4 to $1.8 \mathrm{~m}^{2} / \mathrm{sow}$ with no further decline above $1.8 \mathrm{~m}^{2} / \mathrm{sow}$. This study also found that, similar to aggression, although space affected cortisol at $\mathrm{d} 2$, there was no evidence that space affected basal cortisol concentrations at d 9 and 51 after mixing. Sows may adapt physiologically as well as behaviorally to spatial restriction. However, scientific evidence for such an effect is limited to a few studies in rodents (see Hemsworth et al., 2013). When sows were mixed after pregnancy confirmation, Salak-Johnson et al. (2012) found no effect of space on plasma cortisol, perhaps owing to the fact that physiological stress is affected by stage of reproduction, 
Table 1. Summary of literature regarding the effect of increasing space allowance on measures of sow welfare

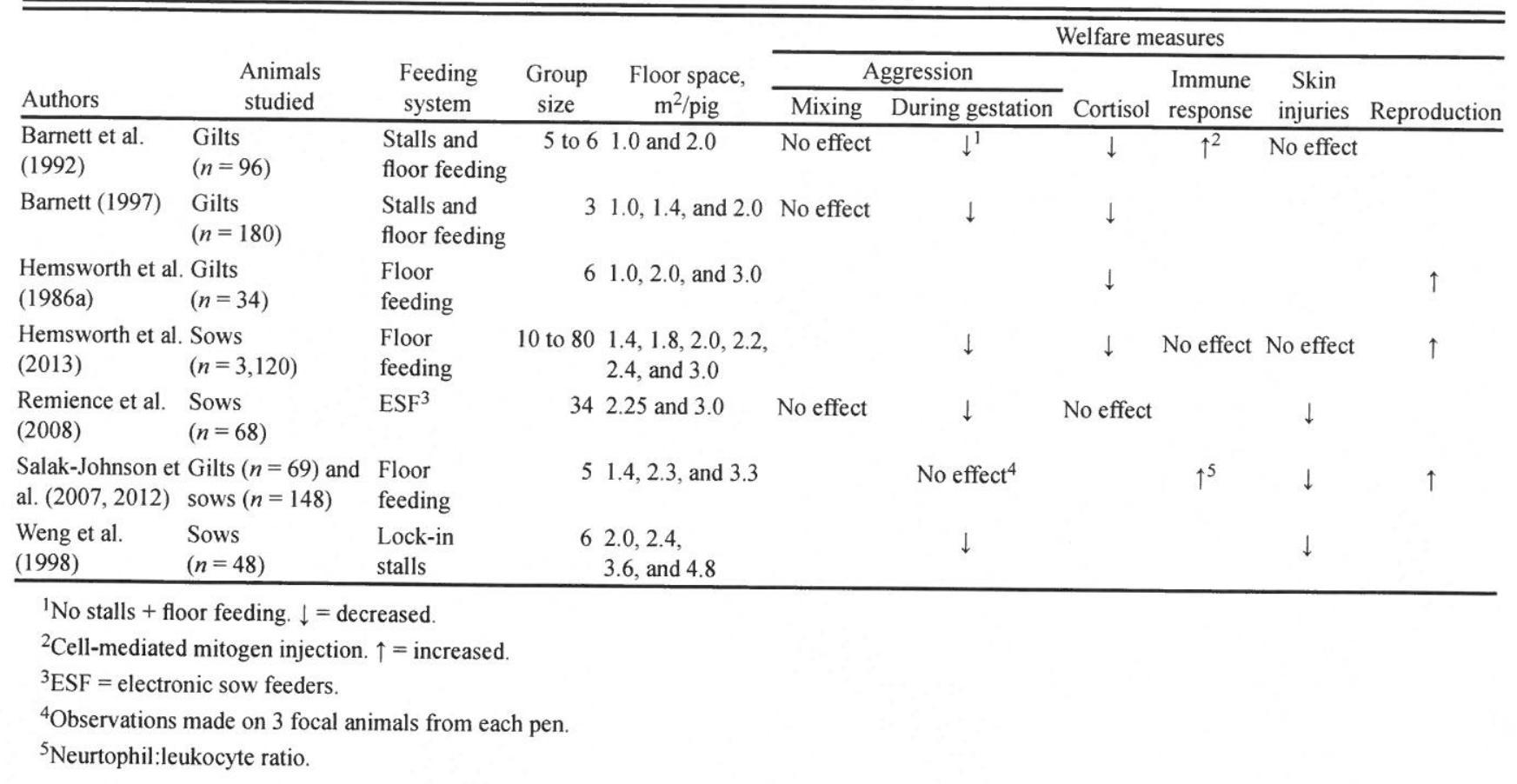

a phenomena that is discussed later in this review (see Stage of Reproductive Cycle at Mixing).

Although studies by Barnett (1997) and Hemsworth et al. (2013) all found that space affected aggression and stress, there were no effects of space on skin injuries. By contrast, Weng et al. (1998) and Salak-Johnson et al. (2007) found skin injuries increased as floor space decreased. Similarly, Remience et al. (2008) found that sows housed in dynamic groups had more fresh superficial injuries and deep skin injuries at a smaller space allowance. Barnett et al. (2001) suggested that in very confined conditions, the consequences of fighting on skin injuries might be reduced because there is less space to inflict injury. However, several differences between these experiments may also account for these conflicting results. For example, some studied gilts whereas others studied sows; some studied gilts and sows once confirmed pregnant (Hemsworth et al., 1986a; Barnett, 1997; Weng et al., 1998; Salak-Johnson et al., 2007; Remience et al., 2008), whereas Hemsworth et al. (2013) studied sows soon after insemination. Management practices such as floor feeding and electronic sow feeders (ESF) and static and dynamic groups also varied.

Increases in immunological responsiveness (assessed on the basis of a cell-mediated response to a mitogen injection [Barnett, 1997] and neutrophil:leukocyte ratio [Salak-Johnson et al., 2012]) and reproduction (based on the percentage of gilts detected in estrus [Hemsworth et al., 1986a], percentage of sows mated that farrowed [Hemsworth et al., 2013], and litter size [Salak-Johnson et al., 2007]) have also been reported to be higher at a greater floor space allowance.
It is commonly suggested that space requirement may interact with the number of animals in a group, in that space requirements of gestating sows may be less in larger groups. In the experiment by Hemsworth et al. (2013), there was no evidence of an appreciable confounding due to group size effects, for pens having between 10 and 80 sows, on aggression, stress, and reproduction. However, it should be noted that space may interact with other pen design features, such as location of key resources and the presence of visual and physical barriers.

In conclusion, this literature indicates that space affects aggression, injuries, and stress, particularly early after mixing. However, the space allowance at which sow welfare is compromised is difficult to assess from these results except that $1.0 \mathrm{~m}^{2} /$ gilt is insufficient in gilts and $1.4 \mathrm{~m}^{2} / \mathrm{sow}$ is insufficient in sows. Clearly, further research is required to examine the effects of space allowance in the range of 1.8 to $2.4 \mathrm{~m}^{2} /$ sow in more detail, with particular attention given to the effects of space early after insemination because this is the period when effects on aggression, stress, and reproduction are likely to be most pronounced. Research is also required to examine the effects of reducing space during gestation because there may be opportunity to provide increased space immediately after mixing and decrease space thereafter- that is, staged-gestation penning.

Group Size. It was previously expected that aggression would increase in large groups because there are more dominance relationships to establish (Arey and Edwards, 1998). However, more recent reviews have concluded that there is no evidence to suggest there 
is more aggression in large groups of up to 40 sows in experimental settings and up to 300 sows in industry settings (Barnett et al., 2001; Spoolder et al., 2009). Taylor et al. (1997) found that when sows were housed in groups of 5, 10, 20, and 40 animals, large groups showed greater levels of aggression for $2 \mathrm{~d}$ after mixing. Furthermore, although there was no effect of group size on the frequency of fighting in the first hour after mixing, the duration of fighting increased with group size. By contrast, Hemsworth et al. (2013) reported no difference in the frequency of aggression at feeding at $\mathrm{d} 2$ and 8 after mixing sows into groups of 10,30 , and 80 . There is no obvious reason for this discrepancy; however, there is a substantial body of research in the young pig indicating that aggression does not increase with group sizes in the range of 6 to 80 pigs (Nielsen et al., 1995; Turner et al., 1999, 2000; Samarakone and Gonyou, 2009).

One explanation for why the above results from Hemsworth et al. (2013) and from studies in the young pig contrast with the previous expectation stated in Arey and Edwards (1998) that aggression would increase with group size is that the social behavior of pigs in large groups may differ from that in small groups. In large groups, where individual recognition becomes less likely, animals may use methods other than aggression to establish social dominance. For example, characteristics such as body size might be used to assess the fighting ability of others and thus influence whether or not an animal engages in aggression (D'Eath and Keeling, 2003; Rodenburg and Koene, 2007). Alternatively, in large groups there are more animals to provide shelter for targeted sows, allowing them to hide behind others or escape into the group (Turner and Edwards, 2004; Anil et al., 2006; Spoolder et al., 2009). In addition to this noninterventionist strategy, sows may form subgroups, similar to those in the wild (Gabor et al., 1999), that avoid mixing and within which social hierarchies may develop (Anil et al., 2006; RodríguezEstévez et al., 2010). The rationale underpinning this theory is that the subdivision of the group into smaller subgroups allows for an efficient dominance hierarchy to be preserved among individuals in regular proximity (see Rodríguez-Estévez et al., 2010). Indeed, subgroups have been observed in groups of 40 sows at least in terms of lying behavior (Taylor et al., 1997). However, as Gonyou (2001) notes, it is not clear whether these subgroups are distinct during activity or exist only during lying. If subgroups remain distinct during activity, it suggests territorial or at least well-defined home ranges within pens with large groups.

The relationship between group size and injury is similarly controversial. Although Taylor et al. (1997) found no effect of group size on skin injuries at $\mathrm{d} 5$ and 53 after mixing, Hemsworth et al. (2013) found that sows in groups of 10 consistently had fewer skin injuries than those in groups of 30 and 80 . The authors suggested that locomotion and, therefore, the opportunity to slip and interact with other sows might be inhibited in small groups. Olsson et al. (1994) also reported group size effects on skin injuries, but group size was confounded by space, feeding system, and the presence of bedding. However, as discussed earlier, although aggression is likely to lead to skin injuries (Turner et al., 2006), contact with pen features, particularly due to fast movement in large pens, may also increase the incidence of skin injuries (Karlen et al., 2007).

Nonetheless, both Taylor et al. (1997) and Hemsworth et al. (2013) agreed that group size had no effect on reproductive performance. Furthermore, in relation to cortisol concentrations, Barnett et al. (1984, 1986) found that gilts housed in pairs had increased cortisol compared with those housed in groups of 4 or 8 with a similar space allowance. However, in larger groups of sows $(10,30$, and 80$)$, cortisol at d 2, 9, and 51 was not affected by group size (Hemsworth et al., 2013).

Therefore, although the literature on effects of group size on aggression and injuries are contradictory, there is no evidence that large group sizes of 20 to 80 affect stress or reproductive performance. However, there is evidence in one experiment that sow injuries, but not aggression, increases in larger groups (Hemsworth et al., 2013), whereas another indicates that sow aggression, but not injuries, increases in larger groups (Taylor et al., 1997). Although research with young pigs provides support for the finding by Hemsworth et al. (2013), sows differ from young pigs in age, experience, physiological state, and housing systems. Consequently, more research may provide further clarity on the effects of group size on sow aggression and injuries.

Static and Dynamic Groups. The typical social unit for pigs in wild populations is a basic and relatively stable group of 2 to 4 related sows and their offspring (Gonyou, 2001). However, in most commercial grouphousing systems, sows are abruptly mixed at least once in each reproductive cycle, and this may create a socially unstable environment resulting in increased aggression and injury (Edwards, 1992). Commercial groups of sows can be managed as either a static group, in which the group composition remains stable after formation, or a dynamic group, in which sows are regularly removed from or introduced to the group. Static groups are mostly formed after weaning or mating so that unfamiliar sows are mixed only once per gestation. On the other hand, unfamiliar sows in dynamic systems are frequently introduced to the group so that they experience between 3 and 12 mixings per gestation (Marchant-Forde, 2009).

Although some authors have suggested that problems with aggression may be greater in dynamic groups 
of sows (Arey and Edwards, 1998; Barnett et al., 2001), recent evidence does not necessarily support this interpretation. This hypothesis may be founded on studies such as Durrell et al. (2002), where aggression temporarily increased each time an unfamiliar group of sows was introduced to a dynamic group. However, in a study of 310 sows housed in dynamic groups (mixed at 2-wk intervals in groups totaling about 100 sows), twice-mixed groups (2-wk interval in groups totaling about 100 sows), and static groups of different sizes that were fed with an ESF, Anil et al. (2006) found that although skin injury scores were greatest in the dynamic group both in general and $2 \mathrm{wk}$ after mixing, there were no effects on aggression, cortisol concentrations, farrowing performance, and longevity. Similarly, in a study of 293 sows, Strawford et al. (2008) found no differences in aggression, skin injuries, and cortisol concentrations between sows in static (groups of 34 to 41 sows) and dynamic (mixed at 5-wk intervals in groups totaling about 105 sows) groups with an ESF. However, a recent study by $\mathrm{Li}$ and Gonyou (2013) similarly replaced 35 to 40 sows every $5 \mathrm{wk}$ in a dynamic group and found increased chronic skin injuries (cuts, swellings, and wounds) and lameness in comparison to a static group, although there were no effects on farrowing rate, weight gain, or litter size. These studies differed in a number of management procedures (e.g., the provision of bedding, flooring, and space allowance), and although a space allowance of 1.4 $\mathrm{m}^{2}$ /sow used by Anil et al. (2006) appears suboptimal, the study by Strawford et al. (2008) was confounded by group size. On the other hand, the study by $\mathrm{Li}$ and Gonyou (2013) was considerable, using 1,569 sows over 5 reproductive cycles and $2 \mathrm{yr}$. These conflicting results also suggest that the design of the system may be more important than static and dynamic management per se.

In summary, whereas there are few studies that have specifically compared the two, there is no convincing evidence that sow welfare is adversely affected in dynamic groups in comparison to static groups. Getting other features right, such as pen design in terms of floor space and feeding system, may be more important than whether the group is static or dynamic.

Use of a Mixing Pen. A number of authors have advocated the use of dedicated mixing pens (Edwards et al., 1993; Arey and Edwards, 1998; Barnett et al., 2001). The premise of the mixing pen is that the provision of features that allow avoidance by less aggressive sows while enabling the social hierarchy to form will reduce aggression and, subsequently, injuries and stress at mixing. However, there has been little research on this topic, particularly on the long-term effects when sows are subsequently placed in gestation group systems.

Common suggestions in the literature and anecdotal observations are that the attributes of mixing pens that may reduce aggression include straw or rice hulls and feed, which may provide a distraction (straw or rice hulls also allows a good foothold when fighting or fleeing); easy access to feed; absence of protruding objects or ridge edges that may damage sows (as in any pen); absence of tightly confined areas in which a sow could be cornered and unable to escape from an aggressive sow; and adequate space for sows to turn around and for two sows to easily pass side by side in all places. Indeed research, mainly on gilts, indicates that aggression at mixing is reduced by modifying pen size and shape on the basis that pigs require a minimum space in which to fight; the use of masking odors on the basis that anosmic pigs show reduced aggression; sedation using pharmacological agents; and grouping after dark, on the basis that it is the "normal" sleeping time, or providing feed ad libitum on the basis that restrictively fed pigs may prefer to feed than fight (see review by Barnett et al., 2001). Although Barnett et al. (2001) concluded that all or some of these above methods may be effective in only postponing aggression, rather than reducing it, the aim when mixing sows should be to introduce the sows in a setting in which individuals can avoid aggressive ones when required with minimum risk to injury and stress while also allowing the social hierarchy to quickly form.

The design of such a mixing pen requires discussion. Although aggressive displays may be initially inhibited, one of the most obvious features of a mixing pen that will reduce aggression and stress is increased floor space (Barnett et al., 1992, 1993). Furthermore, a sow's requirement for space may be less once the group is established (Hemsworth et al., 2013). Therefore, research is required to examine the effects of increased space in a mixing pen on aggression and stress as well as the duration of housing in the mixing pen before space can be reduced without adverse effects.

In addition to increased space, the shape of the mixing pen may be an important determinant of both the quantitative and qualitative aspects of aggression (Barnett et al., 1993). For example, there is limited evidence that aggression at mixing is reduced in rectangular pens compared to square (Barnett et al., 1993) or round pens (Wiegand et al., 1994). Furthermore, including a solid visual barrier in the pen reduces the frequency of aggressive interactions after mixing, although it has no affect on the frequency of fights (see review by Marchant-Forde and Marchant-Forde, 2005). Therefore, a barrier may support active avoidance by visually isolating retreating sows from more dominant animals. Indeed, Edwards et al. (1993) found that barriers consistently reduced total aggression by nearly $30 \%$ in the $12 \mathrm{~h}$ after mixing, whereas van Putten and van de Burgwal (1990) suggest that partitions reduce skin injuries in grouped sows. The presence of feeding stalls 
in the mixing pen may also protect submissive sows that use them as a "retreat" when avoiding aggressive animals (Olsson and Samuelsson, 1993). Barnett et al. (1992) found that partial stalls reduced the number of aggressive interactions in the $90 \mathrm{~min}$ after mixing, regardless of space allowance. However, in a later study, Barnett et al. (1993) found no effects of feeding stalls on aggression or skin injuries up to $90 \mathrm{~min}$ after mixing. The authors stated that there was no apparent explanation for the discrepancy, aside from perhaps differing pen shapes. Further research is required to determine the effects of feeding stalls over several days after mixing as the social order establishes and aggression decreases.

In relation to providing feed in the mixing pen as a strategy to reduce aggression around mixing, Barnett et al. (1994) found that placing feed on the pen floor at mixing did not reduce aggression in the 90 min after mixing, compared to a control pen with no feed on the floor. The provision of feed for ad libitum intake for 24 and $48 \mathrm{~h}$ after mixing did not affect skin injuries in gilts but reduced aggressive interactions for the period of time that the ad libitum feed was present. However, observations on aggression were conducted only at the time that control, floor-fed gilts were fed.

There has been some interest in recent years regarding the effects of boar presence on sow aggression, injuries, and stress after mixing. The hypothesis is that presence of a "supradominant" boar at mixing suppresses aggression in the sows (Marchant-Forde and Marchant-Forde, 2005). Results on the effects of boar presence on sow aggression and injuries are variable (see review by Marchant-Forde and Marchant-Forde, 2005). In one well-controlled study in which stocking density was also examined, the presence of a boar reduced aggression and skin injuries over $28 \mathrm{~h}$ after mixing (Docking et al., 2001). More recently, Borberg and Hoy (2008) reported that the presence of a boar in the pen at mixing reduced the frequency of fights but had no effect on the frequency of aggression, whereas Séguin et al. (2006) found no effects on the frequency of fights at mixing or aggression at feeding at $\mathrm{d} 2$ after mixing compared to a control pen. Neither study found effects of boar presence on skin injuries, and Séguin et al. (2006) did not find effects of boar presence on cortisol concentrations. Borberg and Hoy (2008) suggested that lack of treatment effects might be due to the fact that the boar is not a natural part of the sow social structure. However, as described by MarchantForde and Marchant-Forde (2005, p. 66N), "the largest problems with experiments on boar presence are the confounding factors of group size and space."

After reviewing the literature, it appears that a mixing pen with increased floor space, barriers, and feed supplied ad libitum is likely to reduce aggression at mixing while also enabling the social hierarchy to form. Further research is required to examine the effects of features of mixing pens, such as floor space, visual barriers, feeding stalls, straw or bedding, and feed for ad libitum intake, on aggression, injuries, and stress in both the short and long term. Furthermore and most importantly, other questions that need to be examined are whether changes in the design of the housing system after grouping in the mixing pen, such as another feeding system or introduction to a dynamic group, initiate increases in aggression and stress.

\section{Nutrition and Hunger}

Feeding Level. The feed intake of breeding sows is commonly restricted to prevent excess BW gain and fat deposition, which can cause farrowing and locomotion problems and subsequently reduce reproductive performance (Meunier-Salaün et al., 2001). However, underfeeding may also adversely affect reproductive performance (Virolainen et al., 2004, 2005; Langendijk and Peltoniemi, 2013).

Restricted level of feeding during gestation is generally sufficient in the pork industry for maintenance and fetal development, suggesting that animals are not in a negative energy balance. However, restricted feeding results in behavioral signs of hunger such as increased competition for feed or access to feeding areas (Barnett et al., 2001) and an increased willingness to work for a feed reward (e.g., Lawrence and Terlouw, 1993). Indeed, operant conditioning studies have shown that boars and sows are prepared to work for a feed reward to a degree that suggests that they are hungry for a considerable period of the day (Hutson, 1991; Lawrence and Terlouw, 1993). Furthermore, Bergeron et al. (2000) found that sows fed a control diet for ad libitum intake obtained fewer feed rewards in an operant conditioning test than restrictively fed sows. However, working for feed in itself could be rewarding, because even those sows fed ad libitum worked to obtain some feed reward.

The significance of stereotypies to animal welfare is controversial (Mason and Latham, 2004), but some have argued that the welfare of the animal is at risk if stereotypies occur for $10 \%$ of an animal's waking life (Broom, 1983) and if they occur in more than 5\% of all animals (Wiepkema, 1983). In a review of the literature, Mason and Latham (2004, p. S64) stated that "stereotypies should always be taken seriously as a warning sign of potential suffering, but never used as the sole index of welfare." Lawrence and Terlouw (1993) proposed that feed restriction and the inability to express foraging behavior are a major cause of the development of stereotypies in sows, such as repetitive chain and bar manipulations. They argued 
that when sows are fed a restricted diet, the positive feedback effects of feed consumption, experienced in the early stages of a meal, are not strong enough to override the negative feedback from the ingestion of nutrients, resulting in greater levels of feeding motivation after the meal than before it. Consequently, in an environment where appetitive behavior cannot be performed in a satisfactory way, such behavior may be performed repetitively with a less appropriate substrate (Lawrence and Terlouw, 1993). Indeed stereotypies have been shown to develop in feed-restricted sows (Terlouw et al., 1991; Bergeron et al., 2000).

Grouped sows fed $1.8 \mathrm{~kg}$ (23 MJ DE/d) in "lock-in" stalls spent more time standing and manipulating bars and chains after feeding than sows fed $3.2 \mathrm{~kg}$ (40 MJ $\mathrm{DE} / \mathrm{d}$ ), although there were no effects on aggression or skin injuries (Spoolder et al., 1995). Although the study conducted by Spoolder et al. (1995) was confounded by the presence of straw and sows were locked in the feeding stall for $1 \mathrm{~h}$ after mixing, Spoolder et al. (1997) reported similar results when sows in dynamic groups with deep-litter straw were fed with an ESF (3.0 kg [38 $\mathrm{MJ} \mathrm{DE} / \mathrm{d}]$ and $1.6 \mathrm{~kg}[20 \mathrm{MJ} \mathrm{DE} / \mathrm{d}])$.

It is also of interest that Bergeron and Gonyou (1997) found that sows fed either a high-energy diet (23.7 MJ DE $/ \mathrm{kg}$ ) or a "high-foraging" diet (a standard $\operatorname{diet}[14.0 \mathrm{MJ} \mathrm{DE} / \mathrm{kg}]$ but with a device in the feeder that increased the feeding time) spent less time active and less time displaying stereotypies than sows fed a standard diet (14.0 MJ DE/kg). Therefore, the lack of energy in the diet as well as time spent feeding may contribute to the development of stereotypies. However, although increased feeding times have been shown to reduce sow hunger, in sequential feeding systems such as the ESF, it can cause crowding, thereby reducing overall feeder capacity (Bench et al., 2013a).

In their review of the literature, Meunier-Salaün et al. (2001) reported that there is no consistent evidence of increased stress, based on plasma and urinary cortisol concentrations, in individually housed sows that are feed restricted. More recent studies have similarly reported no effect of feed restriction on cortisol concentrations in pigs, even though there were clear changes in metabolic and behavioral indicators of hunger (de Leeuw and Ekkel, 2004; Toscano et al., 2007). Corticosteriods can be affected by metabolic rate, and, consequently, it has been suggested that cortisol might not be an appropriate physiological measure of stress associated with hunger (de Jong et al., 2002).

Therefore, although stereotypies have been shown to develop in feed-restricted sows, there is no consistent evidence in the few studies that have been conducted of increased aggression, stress, or injuries especially when sows are group-housed.
Fiber (including Foraging Substrates). Increasing fiber content (e.g., inclusion of high-fiber ingredients such as oat hulls, straw, sugar beet pulp, and wheat bran in sow diet) prolongs feeding time and gastrointestinal distension, hence lengthening the time it takes to metabolize food, which subsequently increases satiety and reduces feeding motivation (Robert et al., 1997). However, the literature on the impact of a high-fiber diet on feeding motivation at first glance appears contradictory.

Using operant conditioning tests, Lawrence et al. (1989), Ramonet et al. (1998, 2000), Bergeron et al. (2000), and Jensen et al. (2012) have all shown that feeding restrictively fed pigs high-fiber diets does not affect their operant responses to a feed reward, suggesting that they are still hungry. Conversely, Robert et al. $(1997,2002)$ showed that fiber can reduce feeding motivation in an operant conditioning test. Differences in methodology, such as the feeding schedule, duration and time of day of the tests, food reward, fiber content and quality, and feeding levels, may account for these contrary findings. For example, Robert et al. (1997) and Jensen et al. (2012) used their experimental high-fiber diet as a reward, whereas other investigations used a standard diet (Lawrence et al., 1989; Hutson, 1991; Ramonet et al., 1998; Bergeron et al., 2000).

There is indirect evidence that incorporating fiber in the sow diet reduces feeding motivation. de Leeuw et al. $(2004,2005)$ found that the inclusion of a high level of a fermentable dietary fiber ( $900 \mathrm{~g}$ sugar beet pulp twice daily) may be effective at reducing hunger, as indicated by stabilized blood glucose and insulin levels and reduced activity for several hours after a meal. Furthermore, self-directed behaviors reduced with an increasing level of fermentable dietary fiber, an effect that was most pronounced directly after feeding (de Leeuw et al., 2005). In addition to the studies by de Leeuw et al. (2004, 2005), time spent either active, displaying stereotypies, or both are reduced in restrictively fed gilts and sows fed a high-fiber diet (Robert et al., 1993, 2002; Brouns et al., 1994, 1995; Bergeron et al., 2000; Danielsen and Vestergaard, 2001; Zonderland et al., 2004; de Leeuw et al., 2004, 2005). For example, Bergeron et al. (2000) found that sows fed a control diet ad libitum spent less time displaying stereotypies than sows fed a very high fiber diet $(4.5 \mathrm{~kg} / \mathrm{d}$ [ $23 \%$ crude fiber] of an oat hull diet), who in turn spent less time displaying stereotypies than sows fed a restricted control diet $(2.5 \mathrm{~kg} / \mathrm{d})$. By contrast, some studies have found little or no effects of dietary fiber on stereotypies (2.75 $\mathrm{kg} / \mathrm{d}$ [ $600 \mathrm{~g}$ sugar beet pulp/kg] of a high-fiber diet; Whittaker et al., 1998, 1999). The study by Bergeron et al. (2000) and those conducted by Whittaker et al. $(1998,1999)$ differ both in feeding rate and source of dietary fiber, making comparisons between the studies 
difficult. Further research may provide clarity as to the effects of dietary fiber on stereotypies.

There is limited evidence that high-fiber diets may also affect sow aggression. For example, in one of few investigations to have examined the effects of fiber on aggression, Danielsen and Vestergaard (2001) reported that high-fiber diets ( $500 \mathrm{~g}$ sugar beet pulp $/ \mathrm{kg}$ ) reduced aggression (measured 7 to 9 and 13 to $14 \mathrm{wk}$ after insemination) and sham chewing for trough-fed gilts in small groups and sows in gestation crates. In contrast, Whittaker et al. (1999) found that a high-fiber diet $(600 \mathrm{~g}$ sugar beet pulp/kg) did not reduce aggression around feeding (averaged from 4, 5, 11, and $12 \mathrm{wk}$ after insemination) when sows were floor-fed in groups of seven, although there were fewer vulva injuries in the high-fiber treatment. These two studies differed in terms of feeding mechanism, space allowance, and aggression protocols. Furthermore, aggression measures in both of these studies are confounded by the stage of gestation, which may affect sow aggression (Stevens et al., 2015). Clearly, there is the need for further research into the effects of dietary fiber on sow aggression.

Part of the contradictory results on the effect of highfiber diets may be explained by the different sources of fiber used. Indeed, de Leeuw et al. (2008) hypothesized that the effects of dietary fiber on sow hunger and feeding motivation may depend on the specific characteristics of the fiber used rather than total fiber intake. For example, some fibers provide bulk as a result of their course structure (e.g., oat hulls) or water holding capacity (e.g., sugar beet pulp). These insoluble fibers can increase feelings of fullness by prolonging chewing activity and saliva production and increasing gastric distension (see Souza da Silva et al., 2012). On the other hand, soluble fibers, such as pectin, reduce hunger by increasing the viscosity of the lumen contents and delaying gastric emptying (de Leeuw et al., 2008), and highly fermentable fibers, such as sugar beet pulp or soybean hulls, increase the production of short-chain fatty acids that reduce hunger (see Souza da Silva et al., 2012). Souza da Silva et al. (2012) assessed the effects of a bulky (lignocellulose), a soluble (citrus pectin), and a highly fermentable (resistant starch) fiber on sow feeding motivation. They found that sows fed a soluble fiber had a greater motivation to feed than those fed either the bulky or the highly digestible fibers, assessed using an operant conditioning test, a runway test, and feeder directed and stereotypic behaviors.

Foraging materials (e.g., straw, spent mushroom compost, grass silage, and rice hulls) may allow the feeding motivation of unsatiated sows to be channeled into foraging behavior (Boyle et al., 2002) and also act as a secondary feed source (Jensen et al., 2000). Fibrous foraging materials may reduce the time spent active and displaying stereotypies (or both) in restrictively fed gilts and sows (Spoolder et al., 1995; Stewart et al., 2008). For example, in a factorial-designed experiment examining the effects of feeding level (1.8 $\mathrm{kg}$ [23 MJ] and $3.2 \mathrm{~kg}$ [40 $\mathrm{MJ} / \mathrm{d}$ fed in locked feeding stalls) and the provision of a foraging substrate ( 0 and $1.5 \mathrm{~kg}$ straw/sow), Spoolder et al. (1995) found that low-fed sows spent more time manipulating substrates such as feed trough floor, bars, and chains than high-fed sows. However, low-fed sows provided with straw directed more of this activity toward straw (Spoolder et al., 1995). Therefore, in addition to filling the gut and increasing satiation (Jensen et al., 2000 ), the provision of fibrous foraging materials may further improve welfare by increasing environmental complexity and providing an outlet for exploratory behavior (Lawrence and Terlouw, 1993; Spoolder et al., 1995). Further to this, foraging substrates can also reduce injury caused by slipping (Andersen and Bøe, 1999; Heinonen et al., 2013), provide insulation in winter or in cool climates (Barnett et al., 2001), and improve lying comfort (Durrell et al., 1997; O'Connell, 2007).

The literature on the effects of foraging substrates on aggression is conflicting. Anil et al. (2006) suggested that a small quantity of straw might help to divert the attention of sows at mixing, although the provision of straw in a rack increases aggression at mixing in large dynamic pens (Stewart et al., 2008). Limited access to straw may create competition and consequently increase aggression. In their review of the literature, Bench et al. (2013b) indicated that there is an interaction between the effects of straw and feeding regimen. For example, providing straw in a rack increased aggression at the rack but reduced aggression at the ESF (Krause et al., 1997; Stewart et al., 2008). On the other hand, the provision of straw bedding to small stable groups of sows with individual feeding stalls and to a large dynamic pen with an ESF had no effect on aggression (Broom et al., 1995). When sows were floor-fed, Whittaker et al. (1999) found that the provision of straw on the floor before feeding increased aggression and vulva injuries, although skin injuries were unaffected, during $2 \mathrm{~h}$ after feeding. Although floor-fed sows provided with straw bedding spent more time engaged in substrate manipulation, this increased activity also increased the likelihood of chance encounters between sows, with such encounters resulting in aggression (Whittaker et al., 1999).

In conclusion, there is no obvious solution to reduce sow hunger. Although additional fiber, either through the inclusion of dietary fiber or the provision of fibrous foraging materials, may reduce hunger between meals, ad libitum feeding appears to be the most effective way of reducing feeding motivation (Bergeron et al., 2000). One possibility may be to restrictively feed sows a lowfiber diet that is supplemented with ad libitum access to roughage. As several authors have noted (e.g., Bench et 
al., 2013a), there is a need for further research to evaluate widely available and cheap fiber materials and feed grains to develop strategies to control nutrient intake of dry sows feeding ad libitum because of the implications of hunger on sow welfare.

Feeding System. The type of feeding system affects the level of aggression related to competition for feed (Spoolder et al., 2009). One of the simplest and cheapest methods of feed delivery is floor feeding, where feed is either manually or automatically delivered directly onto the pen floor. Feed droppers are normally spread to accommodate approximately 6 to 8 sows per feeder (Marchant-Forde, 2009). This system allows sows to feed simultaneously and thus fulfill some element of natural feeding behavior. However, delivering the total feed allowance onto the floor and leaving each individual to eat as much as she can until all the feed is gone gives rise to aggression between sows as they compete for limited feed (Edwards, 1992). Variation in feed intake between sows can also be seen in floor feeding systems (Mendl et al., 1992; Brouns and Edwards, 1994). This variation is exasperated because younger females are not able to consume their ration as quickly as older females, whereas dominant sows defend their access to feed. Consequently, subordinate sows can become undernourished and exhibit low weight gain (Edwards, 1992). Spreading feed over a greater area can minimize aggression and allow for greater access for subordinate sows (Gonyou, 2005). Alternatively, delivering the daily ration over multiple feed drops per day can reduce skin and vulva injuries and structural problems with feet and legs in gestating group-housed sows, although duration of agonistic behavior was unaffected in young prepubertal gilts (Schneider et al., 2007).

Two alternative feed delivery systems that are commonly used to protect sows from aggression while feeding and to better control individual sow intake are feeding stalls (full or partial) and the ESF. In comparison to floor feeding, the provision of feeding stalls, particularly gated full-body length stalls, reduces aggression and plasma cortisol concentrations in the long term in group-housed gestating gilts (Barnett et al., 1992; Barnett, 1997; Andersen et al., 1999), although they do not effect aggression or skin injuries in the 90 min after mixing or skin injuries in the long term (Barnett et al., 1992; Barnett, 1997). Andersen et al. (1999) found increased vulva bites in pens with full-body feeding stalls and suggested that feeding arrangement influences the nature as well as the amount of aggression. Indeed, although floor feeding is competitive, gaining access to feeding stalls can also lead to competition and aggression between group-housed sows (Bench et al., 2013b). Even when feeding stalls are provided, it is of interest that floor space, either total or outside the feeder, affects aggression and plasma cortisol concentrations (Barnett et al., 1992; Barnett, 1997).

The ESF allows for the greatest possible control over individual sow intake. However, this system forces sows to feed in sequence, and as such, sows queue at the entrance of the feeder and may often use aggression, including vulva biting, to gain priority access (Scott et al., 2009; Olsson et al., 2011; Bench et al., 2013b). Furthermore, after consuming their daily allowance, dominant sows may continue to cycle through the ESF (Hunter et al., 1988; Olsson et al., 2011), placing the system under pressure and preventing subordinate sows from fulfilling their motivation to feed (Durrell et al., 2002). Consequently, preventing queuing has been identified as an important development in improving welfare in ESF systems (Anil et al., 2003). Nonetheless, a distinct advantage of ESF systems is the possibility to control the daily feed intake of individual animals. Restarting the feeding cycle in the evening (Jensen et al., 2000), stimulating the formation of subgroups (van Putten and van de Burgwal, 1990; Kirchner et al., 2012), and considering the number of feeders, feeder design (i.e., distance from exit to reentry), and feeder location (Zurbrigg and Blackwell, 2006) may all help reduce queuing and hence aggression at the ESF.

Apart from observations on skin and vulva injuries, no rigorous comparison of the effects of ESF and other feeding systems has been conducted. Although confounded by floor space and other environmental variables, sows in pens with partial stalls have been shown to have lower aggression levels and fewer skin injuries than sows in pens with an ESF (Broom et al., 1995; Leeb et al., 2001; Durrell et al., 2002; Geverink and Tuyttens, 2007; Geverink et al., 2008), although they may sustain more vulva injuries (Leeb et al., 2001). On the other hand, although Chapinal et al. (2010) found that fewer sows were removed for sudden death, reproductive failure, or failure to feed in a system with partial feeding stalls compared with an unguarded ESF, there were no differences between the systems in terms of both vulva injuries and reproduction. As discussed by Chapinal et al. (2010), the simultaneous feeding of sows from feeding stalls may precede competition for access to the drinkers, therefore highlighting the importance of accessibility to the drinker as well as to the feeder.

In summary, although floor feeding is competitive, accessing feeding stalls or the ESF also leads to competition between group-housed sows. Andersen et al. (1999, p. 102) stated that, "the feeding arrangement may influence the nature of the aggressive encounters as well as the amount of aggression." Feeding stalls may be the compromise, allowing sows to simultaneously feed while offering some form of protection against aggressive animals and reduced feed intake, 
although sows in these systems could be at greater risk of vulva injuries than either ESF or floor feeding systems. Overall, it is difficult to derive conclusions on this topic because research directly comparing aggression, injuries, and intake (i.e., weight gain) between floor feeding, feeding stall, and ESF systems is lacking.

\section{Sow Intrinsic Factors}

Individual Aggressive Behavior. In the wild, intraspecific variation ensures that different individuals thrive under different environmental conditions, thus safeguarding the ongoing survival of the species (Reale and Dingermanse, 2010). However, under intensive housing conditions, one type of animal (dominant or subordinate) may prove to be more successful than another (Mendl and Deag, 1995; Wechsler, 1995). In a study in which pregnant gilts were classified on the basis of their ability to displace others in agonistic interactions (no, low, or high success), low-success gilts had greater basal concentrations of salivary cortisol and were more responsive to an ACTH challenge, both indicative of a chronic stress response, than sows of high or no success (Mendl et al., 1992). Furthermore, low-success gilts had lighter piglets than the other two categories of gilts. Similarly, in comparison to sows of high or no success, socially intermediate sows showed signs of stress, such as elevated cortisol concentrations and reduced natural T killer-cell activity, and had lower farrowing rates and smaller litter sizes (Nicholson et al., 1993). In groups mixed early after insemination, Verdon (2014) found that on days 9 and 51 post-mixing dominant sows (those that delivered more aggression than they received) received less aggression and hence had fewer injuries. They also gained the most weight and experienced the least stress. While subdominant sows (those that delivered less aggression than they received) and submissive sows (those that rarely delivered aggression) were comparable in terms of aggression received, weight gain and reproduction, subdominant sows experienced greater stress but submissive sows had more injuries later in gestation.

There is also evidence that the composition of the group in terms of aggressiveness may affect the overall welfare of the group. Groups of young pigs of varying aggression (high and low as assessed on the basis of the individual's attack latency in a resident-intruder test) displayed less aggression immediately after mixing and had fewer skin injuries compared with grouping pigs of similar aggression (either high or low; Erhard et al., 1997).

In contrast to the young pig, there is limited evidence in sows that the composition of the group in terms of aggressiveness may not affect the overall welfare of the group. Verdon (2014) found that $85 \%$ of recently in- seminated sows that interacted with a fiberglass model pig in an adjacent stall within $3 \mathrm{~s}$ after introduction were subsequently classified when grouped as dominant (delivered more aggression on mixing than they received) or subdominant (received more aggression than they delivered) rather than submissive (delivered no aggression). Therefore, by selecting sows that interacted with a fiberglass model pig within $3 \mathrm{~s}$, Verdon (2014) then assembled groups of sows predicted to be mainly (i.e., $85 \%$ of sows) either dominant or subdominant and compared the welfare of these groups to groups of sows randomly assembled. However, no differences were found early after mixing in aggression, skin injuries, cortisol concentrations, live weight gain, or reproductive performance between the treatments. Although this finding contrasts with previous studies in immature pigs, both the social behavior and social experience of sows are markedly different to that of younger pigs.

Therefore, although sows vary in terms of individual aggressive characteristics, the tendency to show aggression may be less important than the behavior of others in the group. When fighting has significant costs, such as when sows are housed with older sows, otherwise aggressive animals may show flexibility in their use of aggression. Indeed, in studying the heritability of aggression, D'Eath et al. (2009) found that the pen effect explained a considerable part of the variation in the environmental component of aggression, implicating the role of group mates on an individual's aggressive behavior. Clearly, further research is required on the effects of group composition in terms of aggression.

Genetics. The influence of genetics on aggression is well documented in studies on mice and rats (e.g., Benus et al., 1990[) and aggressive behavior traits have been found to be heritable in flies, adolescent humans, and fighting bulls (see Turner et al., 2008). Erhard and Mendl (1997) suggested that differences between litters of growing pigs in attack latency in a resident-intruder test were sufficiently large to suggest possible maternal or genetic effects, and DNA markers have been identified in two genes that also have multiple and consistent associations with aggressive behavior in growing pigs (Muráni et al., 2010). Research on groups of growing pigs have reported a low to moderate heritability $\left(h^{2}=\right.$ 0.26 to 0.46 ) in the frequency and duration of engagement in reciprocal aggression (Turner et al., 2008, 2009; D'Eath et al., 2009; Stukenborg et al., 2012). Evidence in the gilt and sow indicate a moderate heritability for aggression received $\left(h^{2}=0.42\right)$ for $48 \mathrm{~h}$ after mixing (Stukenborg et al., 2012) and a low heritability $\left(h^{2}=\right.$ 0.24 ) for severe aggressive behaviors performed for 30 min after mixing (Løvendahl et al., 2005).

Although genetic selection schemes generally emphasize physical traits of production (e.g., growth, 
number of nipples, and litter size), the transition to group housing requires sows that can harmoniously live in large groups, and as such, social behavior is likely to be considered, in the near future, a highly significant production trait (Stricklin, 2001). Selection for reduced aggression in pigs is feasible and desirable, but as shown by D'Eath et al. (2009), other behaviors such as general activity and ease of handling may have a correlated response to some degree, with possible implications for animal production and welfare. Although Løvendahl et al. (2005) found no genetic relationship between sow aggressiveness and maternal behavior, research in this area is lacking.

In conclusion, genetics is a contributing factor to aggressive trait characteristics in the sow, and therefore, selection against sow aggressiveness appears feasible. However, the full effects of genetic selection against aggression on other traits needs to be understood, and the desirable behaviors possessed by socially "harmonious" sows need to be defined and the heritabilities estimated.

Experience. It is widely accepted that, like other basic behavior, aggressive behavior is strongly influenced by experience. Experience of social aggression modulates aggressive behavior as prior winning experiences raise, and losing experiences lower, an individual's perceived fighting ability (see review by Hsu et al., 2006).

In rats and mice, experience of social aggression leading to a victory increases the chances of attacks in subsequent encounters of the same kind (Kudryavtseva et al., 2004). Although these experiences do not alter actual fighting ability, contest winners in a variety of taxa have been shown to initiate future aggression more readily or more aggressively or both whereas contest losers are more likely to avoid aggression (fish [Hsu and Wolf, 2001], pigs [D'Eath, 2005], and rats [Lehner et al., 2011]). Reinforcing this effect is the determination that being successful in an aggressive interaction is in itself rewarding whereas the punishing effects of defeat are likely to result in avoidance (see review by Potegal, 1979). Animals in paired encounters may also learn to avoid pain inflicted by their opponents by attacking them first. Experience, however, is not the only factor that influences contest outcome; differences in size, condition, or age may also contribute (e.g., Jensen and Yngvesson, 1998). Nevertheless, under commercial conditions, where similarly aged pigs are commonly mixed into groups, aggression may depend increasingly on social experience. Piglets that could socialize with non-litter mates during lactation contacted an unfamiliar piglet more quickly (Hillmann et al., 2003; D'Eath 2004, 2005) and inflicted fewer wounds (Olsson et al., 1999) in a social confrontation test conducted at weaning. Furthermore, although socialized weaner pigs start- ed fighting sooner when mixed into small groups, these fights were shorter and socialized pigs formed a stable hierarchy more quickly than control pigs (Newberry et al., 2000; D'Eath, 2005).

Although social skills for later life are learned predominantly in adolescence, there is little research on the effects of adolescent socialization on aggressive behavior of the adult sow. One exception is an experiment by van Putten and Buré (1997), in which gilts were regrouped 2, 3, or 4 times in the period from $10 \mathrm{wk}$ to 5 mo of age. Gilts that were regrouped 3 or 4 times engaged in significantly fewer aggressive bouts and spent less time in aggression during the $24 \mathrm{~h}$ after mixing (van Putten and Buré, 1997). It would be valuable to continue such an experiment over a longer period of the sow's life cycle or after exposure to older females during the adolescent period. Recent Danish research (Rasmussen, 2012) exposed gilts to sows during rearing and found that, after mixing into dynamic pens for their first gestation, socialized gilts spent more time using the resting areas occupied by older sows than nonsocialized gilts, although exposure to sows was confounded by mixing before insemination. This suggests that the socialized gilts were better integrated into the social structure of the main group of sows. Indeed, the life history of wild European boar involves matriarchal groups (Gabor et al., 1999) and, therefore, the importance of interactions with older sows in developing social skills in the female pig may be vastly underestimated.

Familiarity may also affect aggression at mixing. The total time unacquainted pigs spend fighting after mixing is up to 97 times more than familiar pigs ( $\mathrm{Li}$ and Johnston, 2009). Kennedy and Broom (1996) found that aggression received by pigs individually introduced to groups was reduced when the original group of pigs had previously received $5 \mathrm{~d}$ of auditory or olfactory contact with the individual. Similarly, Kennedy and Broom (1994) reduced aggression received by gilts in groups of five that were mixed into pens of 23 sows by preexposing the females through a mesh gate for $5 \mathrm{~d}$ before mixing. Arey (1999) found that fights were rare between sows that had been housed together 2, 4, or 6 wk earlier. Durrell et al. (2003) examined the effects of introducing small groups of mixed-parity sows to a larger established group either directly or after $5 \mathrm{wk}$ of housing together and found that aggression was reduced between newly introduced sows, and between newly introduced sows and resident sows, when the introduced groups were familiar with each other. Other studies have also demonstrated less aggression among sows that are familiar with one another (Olsson and Samuelsson, 1993; Puppe, 1998). By contrast, Strawford et al. (2008) found no effect of familiarity on aggression. These sows were separated for a minimum of $4 \mathrm{wk}$ when in the farrowing crates and 
$1 \mathrm{wk}$ during breeding, and the authors commented that the percentage of familiar pigs in pens was small.

In conclusion, understanding the development of aggression is imperative to reduce aggression, injuries, and stress. Older, more experienced sows are more aware of their own fighting abilities and effective in assessing the fighting abilities of others. It is recommended that research assess postmixing aggression and welfare in the gilt and sow after exposure to older females during the adolescent period. Mixing sows or a proportion of sows that have been housed together in the previous 4 to $6 \mathrm{wk}$ (i.e., previous gestation) may reduce aggression at weaning or after insemination.

Stage of Reproductive Cycle at Mixing. There are generally 3 stages of reproduction at which sows can be mixed: after weaning, after insemination, or after pregnancy detection. Although most studies have examined the effects of mixing once pregnancy has been confirmed at 28 to $35 \mathrm{~d}$ after insemination, few studies have examined mixing during earlier stages of pregnancy or even before insemination.

There is evidence that the stage of the reproductive cycle at which sows are mixed may affect aggression. This may, in part, be due to changes in hormone levels throughout gestation. For example, Stevens et al. (2015) suggested that, based on studies in rodents (Fraile et al., 1987; Kohlert and Meisel, 2001), aggressive behavior of sows may decrease as progesterone concentrations peak around $\mathrm{d} 16$ of pregnancy and remain elevated until just before parturition. Indeed, sows mixed in the week after insemination (early gestation) were more aggressive early after mixing than those mixed 5 to $6 \mathrm{wk}$ after insemination (late gestation; Stevens et al., 2015). These effects seem to be acute because no differences were evident by $\mathrm{d} 7$ after mixing. By contrast, Strawford et al. (2008) and Knox et al. (2014) found that aggression early after mixing was similar for sows mixed at 2 to $9 \mathrm{~d}$ after insemination or 35 to $46 \mathrm{~d}$ after insemination. Stevens et al. (2015) conceded that there is no apparent explanation for this discrepancy, although both Knox et al. (2014) and Stevens et al. (2015) pointed to sow intrinsic (genetics, size, and experience) and managerial (feeding system, pen design, and group size) factors as a possible explanation.

In accordance with increased frequency of aggressive behavior found at mixing, Stevens et al. (2015) reported greater cortisol concentrations at mixing for sows mixed early rather than late in gestation, and again these differences were not apparent at $\mathrm{d} 7$. By contrast, Knox et al. (2014) found that sows mixed early after insemination had a smaller increase in serum cortisol from a baseline measure than those mixed later. Nonetheless, Spoolder et al. (2009) recommended that stress should be avoided to minimize reproductive failure, especially at 2 to 4 wk of pregnancy, a time in which two sensitive reproductive events occur-attachment of embryos to the endometrium ( 11 to $16 \mathrm{~d}$ ) and shortly thereafter socalled "maternal recognition of pregnancy"-with the associated hormonal changes.

As with cortisol and aggression, there appears to be an acute effect of stage of reproduction at mixing on injuries. For example, Stevens et al. (2015) found that sows mixed early in gestation had more skin injuries at $\mathrm{d} 7$ after mixing than those mixed later in gestation, and Knox et al. (2014) found that sows mixed early in gestation had more skin injuries, a greater incidence of lameness, and more vulva injuries than sows mixed later in gestation. However, these effects were not seen in the long term. Furthermore, Stevens et al. (2015) found no treatment effects on skin injuries at $\mathrm{d} 91$. However, $\mathrm{Li}$ and Gonyou (2013) found that sows mixed early in gestation had more skin injuries before farrowing than those mixed late in gestation. There were differences between studies in the assessment of skin injuries: Li and Gonyou (2013) did not include scratches when counting skin injuries, whereas the other studies did.

The stage of reproduction in which sows are mixed may be associated with specific reproductive concerns Indeed, conception rates were lower for sows mixed early in gestation than for those mixed at late in gestation or those housed in stalls for the entire gestation (Knox et al., 2014), and the farrowing rate of sows mixed early in gestation was lower than for those mixed late in gestation ( $\mathrm{Li}$ and Gonyou, 2013; Knox et al., 2014). However, Danish research (Nielsen, 1999) suggests that there are no effects of grouping restrictively fed sows in dynamic groups early after insemination, rather than $4 \mathrm{wk}$ after insemination, on farrowing rate or litter size. In their review of the literature, Spoolder et al. (2009) suggested that variable results regarding the time of grouping for optimal reproductive performance indicate that other factors, such as the type of housing system and type of sow studied, may be influential.

With the widespread international move away from stall housing of sows, there is likely to be an increasing use of grouping sows at weaning. Algers et al. (2007) suggested that housing sows in stalls around the time of estrus may cause stress and frustration because they cannot adequately express their sexual behavior. However, in groups, dominant sows show more sexual behavior than submissive sows, particularly in terms of mounting other and low-ranking sows, which may increase the risk of leg injuries to both (Pedersen et al., 1993). Group housing may also facilitate the sexual behavior of dominant sows and suppress that of subordinate sows, with dominant sows in pairs showing greater attraction to the boar and receptivity than the subordinate sows, whereas sows housed individually were intermediate (Pedersen 
et al., 2003). The onset of estrus was delayed and variation in the onset of estrus increased (Langendijk et al., 2000; Rault et al., 2014) when sows were housed in groups from weaning, although with high levels of boar stimulation, neither the detection nor duration of estrus differed between weaned sows in stalls and those in groups (Langendijk et al., 2000). Estrus detection protocols may be especially important in group-weaned systems (Kemp et al., 2005; Rault et al., 2014) because fewer sows may be detected early after weaning in groups (Rault et al., 2014). Danish research (Fisker, 1995, 1999) suggests that grouping restrictively fed sows in static groups at weaning or early after insemination, rather than $4 \mathrm{wk}$ after insemination, reduced total born piglets (by 0.6 and 0.5 piglets per litter, respectively) but did not affect farrowing rate. However, there is very little scientific literature on the effects of grouping at weaning on sow welfare. A recent study reported that sows mixed into groups at weaning had greater cortisol concentrations than those mixed within $2 \mathrm{~d}$ after insemination, which could be due either to the stage of reproduction or the accumulation of various stressors when weaning sows into groups (Rault et al., 2014).

To conclude, it appears that the challenges associated with aggression, stress, and injuries at mixing have the greatest implications for sows mixed early after insemination. Consequently, research needs to focus on this stage of the reproductive cycle. The effects of group housing from weaning on both the onset and the detection of estrus as well as sow reproduction and welfare also requires further research.

Parity. High social rank is correlated with sow weight and parity, with heavier sows typically being older and more dominant (Brouns et al., 1994; Arey, 1999; D'Eath et al., 2009), although there are exceptions (Mount and Seabrook, 1993; Brouns and Edwards, 1994). Therefore, how the group is managed, in terms of the distribution of parities, may affect aggression, injuries, and stress.

In mixed parity groups, Jansen et al. (2007) reported that gilts fought less in the $2 \mathrm{~d}$ after mixing than sows of parity 1 or 3, whereas when Moore et al. (1993) introduced mixed parity sows into a dynamic group, the sows fought more for $3 \mathrm{~h}$ after mixing than the gilts. Similarly, older sows (parity 4 to 9 ) were involved in more aggressive encounters for $4 \mathrm{~h}$ after mixing than young (parity 1) and intermediate (parity 2 to 3 ) sows (Strawford et al., 2008). However, when parity 1 sows are housed with gilts rather than with older sows, they won more fights after mixing, sustained fewer scratches, gained more weight, and had greater farrowing rates, suggesting they were dominant to gilts in a pen but subordinate to sows ( $\mathrm{Li}$ et al., 2012). Aside from the report by Strawford et al. (2008) that parity did not affect aggression at an ESF throughout gestation, possibly because younger sows fed later, few studies have examined long-term effects of parity on aggression.

Older sows have also been reported to have greater total injury scores than younger sows in mixed parity groups (Hodgkiss et al., 1998; Strawford et al., 2008). By contrast, Anil et al. (2003) found that the likelihood of a greater total injury score decreased from parity 1 to 2 , but this association was inconsequential by parity 3 (Anil et al., 2003). Differences between these studies are likely due to variation in injury scoring protocol (i.e., fresh vs. total injuries and count of injuries vs. categorization), although differences in pen design and managerial practices may have also contributed.

There is only one study that reported on the effects of housing sows in uniform parity groups, finding that in such groups gilts fought less than parity 1 or 2 sows (see review by Spoolder et al., 2009). However, variation in age exists in natural groups of pigs (Gonyou, 2001), and such diversity may be integral to social learning and stabilization of the social group. Considering the potential benefits of reducing aggression and stress in gilts and young sows, more research is clearly required to determine whether the above reported effect is real.

To summarize, the literature suggests that in mixed parity groups, older sows will fight with each other for dominance after mixing but may also deliver aggression to younger sows that are subordinate. This highlights the need for increased space and the provision of barriers in the pen at mixing to facilitate active avoidance by younger sows. This area of study would benefit from further research into the long-term effects of parity on sow aggression, injuries, and stress. Alternatively, gilts and parity 1 sows could be housed either together or in single-parity groups, but more research is required to determine the immediate and long-term effects of creating such a social group.

\section{"Stockmanship"}

As reviewed by Hemsworth and Coleman (2011), there are three main lines of evidence demonstrating the impact of stockpeople on the welfare of pigs and other farm animals: handling studies in controlled experimental conditions, observations in commercial settings, and intervention studies in commercial settings. Conditioning and habituation to humans, occurring both early and later in life, are the most influential factors affecting the behavioral responses of farm animals to humans. The results of handling studies in the laboratory and intervention studies on farms, using cognitive behavioral training of stockpeople, on the relationships between stockperson attitudes, stockperson behavior, animal behavior, and stress physiology 
provide evidence of causal relationships between these variables (Gonyou et al., 1986; Hemsworth et al., 1981a,b, 1986b, 1987, 1989, 1994). This body of research highlights the importance of the stockperson on animal welfare and provides the evidence for pronouncements such as that in British Codes of Recommendations for the Welfare of Farm Livestock (Department for Environment, Food and Rural Affairs, 2003 , p. 3) that, "No matter how acceptable a system may be in principle, without competent, diligent stockmanship, the welfare of the animals cannot be adequately catered for."

Apart from effects of poor handling on stress, poor stockperson attitudes are likely to lead to reduced commitment to the surveillance of, and the attendance to, welfare and production issues (Hemsworth and Coleman, 2011), and this is likely to be of greater consequence in group-housing than stall-housing situations.

It is likely that in the near future both the livestock industries and the general community will place an increasing emphasis on ensuring the competency of stockpeople to manage the welfare of livestock (Hemsworth and Coleman, 2011). Even though welfare monitoring schemes are likely to improve animal welfare, the impact of such schemes will be realized only by recognizing the limitations of stockpeople, monitoring stockmanship, and providing specific stockperson training to target key aspects of stockmanship (Hemsworth et al., 2009).

\section{CONCLUSIONS AND FUTURE RESEARCH DIRECTIONS}

Factors that have been shown to impact the welfare of group-housed sows have been discussed in this review. The greatest influence appears to be space allowance. In addition to spatial requirements for physical size and basic movement, pigs need to access key resources such as feed, water, and lying space. They are also motivated to interact with other sows and to explore (particularly if hungry). Therefore, they need space not only to access the resources but also, if necessary, to distance themselves from others, including when accessing these resources. Further research is required to examine the effects of space allowance in the range of 1.8 to $2.4 \mathrm{~m}^{2} / \mathrm{sow}$ in more detail. In addition to quantity of floor space, the quality of space is also important; spatial separation between sows can be provided with visual or physical barriers and stalls.

The period immediately after mixing has a pronounced effect on aggression and stress, and therefore, the use of a dedicated mixing pen may reduce aggression, injuries, and stress around mixing. However, the important features of a mixing pen, particularly extra floor space and visual barriers, requires further examination before rigorous recommendations on its design can be made. The duration of housing in the mixing pen before sows can be transferred to gestation housing without adversely affecting aggression and stress also requires examination.

Another factor of considerable importance is hunger because of its implications on competition for feed or access to feeding areas in sows that are restively fed. Opportunities to prolong satiety between meals through higher feeding levels and provision of additional fiber, either in the diet or through access to a foraging substrate or both, should be examined because of their implications on stereotypies and aggression. However, the feeding system may also affect aggression and stress. In comparison to floor feeding, the provision of full-body feeding stalls reduces aggression and stress. Further research directly comparing floor feeding, feeding stalls, and ESF systems is required.

Both experiential and genetic factors are also related to sow aggression, injuries, and stress. Sows are able to recognize previous pen mates after being separated for up to $6 \mathrm{wk}$, and consequently, mixing sows or a proportion of sows that have been housed together in the previous gestation may reduce aggression. Exposing juvenile gilts to sows (socialization) may facilitate more rapid and safe development of the social hierarchy when these females are subsequently mixed with unfamiliar females in later life. Therefore, the potential effect of socializing juvenile gilts on aggression, injuries, and stress of sows mixed in later life is clearly warranted. Furthermore, developments in the understanding of genetic selection against aggression and its broader implications on sow welfare and productivity should be closely examined and used, if feasible and practical, to minimize sow aggression.

Even though few studies have been conducted, there is evidence of social effects on sexual behavior and variation in the onset and detection of estrus when sows are grouped at weaning. Clearly, further research on the effects of grouping sows at weaning on aggression, injury, and stress in a variety of housing systems is required, particularly as the pork industry moves away from stall housing of sows.

\section{LITERATURE CITED}

Algers, B., M. Sanaa, T. Nunes, B. Wechsler, H. A. M. Spoolder, M. C. Meunier-Salaün, and L. J. Pedersen. 2007. Scientific report on animal health and welfare aspects of different housing and husbandry systems for adult breeding boars, pregnant, farrowing sows and weaned piglets. EFSA J. 572:1-107.

Andersen, I. L., and K. E. Bøe. 1999. Straw bedding or concrete floor for loose-housed pregnant sows: Consequences for aggression, production and physical health. Acta Agric. Scand., Sect. A 49:190-195. 
Andersen, I. L., K. E. Bøe, and A. L. Kristiansen. 1999. The influence of different feeding arrangements and food type on competition at feeding in pregnant sows. Appl. Anim. Behav. Sci. 65:91-104. doi:10.1016/S0168-1591(99)00058-1.

Anil, L., S. S. Anil, J. Deen, S. K. Baidoo, and R. D. Walker. 2006. Effect of group size and structure on the welfare and performance of pregnant sows in pens with electronic sow feeders. Can. J. Vet. Res. 70:128-136.

Anil, L., K. M. Bhend, S. K. Baidoo, R. Morrison, and J. Deen. 2003. Comparison of injuries in sows housed in gestation stalls versus group pens with electronic sow feeders. J. Am. Vet. Med. Assoc. 223:1334-1338. doi:10.2460/javma.2003.223.1334.

Arey, D. S. 1999. Time course for the formation and disruption of social organization in group-housed sows. Appl. Anim. Behav. Sci. 62:199-207. doi:10.1016/S0168-1591(98)00224-X.

Arey, D. S., and S. A. Edwards. 1998. Factors affecting aggression between sows after mixing and the consequences for welfare and production. Livest. Prod. Sci. 56:61-70. doi:10.1016/ S0301-6226(98)00144-4.

Barnett, J. L. 1997. Modifying the design of group pens with individual feeding places affects the welfare of pigs. In: R. W. Bottcher and S. J. Hoff, editors, Proc. 5th Int. Symp. American Soc. Agri. Engineers., St. Joseph, MI. p. 613-618.

Barnett, J. L., G. M. Cronin, T. H. McCallum, and E. A. Newman. 1993. Effects of pen size/shape and design on aggression when grouping unfamiliar adult pigs. Appl. Anim. Behav. Sci. 36:111-122. doi:10.1016/0168-1591(93)90003-8.

Barnett, J. L., G. M. Cronin, C. G. Winfield, and A. M. Dewar. 1984. The welfare of adult pigs: The effects of five housing treatments on behaviour, plasma corticosteroids and injuries. Appl. Anim. Behav. Sci. 12:209-232. doi:10.1016/01681591(84)90115-1.

Barnett, J. L., and P. H. Hemsworth. 2009. Welfare monitoring schemes: Using research to safeguard the welfare of animals on the farm. J. Appl. Anim. Welf. Sci. 12:114-131. doi:10.1080/10888700902719856.

Barnett, J. L., P. H. Hemsworth, G. M. Cronin, E. C. Jongman, and G. D. Hutson. 2001. A review of the welfare issues for sows and piglets in relation to housing. Aust. J. Agric. Res. 52:1-28. doi:10.1071/AR00057.

Barnett, J. L., P. H. Hemsworth, G. M. Cronin, E. A. Newman, T. H. McCallum, and D. Chilton. 1992. Effects of pen size, partial stalls and method of feeding on welfare-related behavioural and physiological responses of group-housed pigs. Appl. Anim. Behav. Sci. 34:207-220. doi:10.1016/S0168-1591(05)80116-9.

Barnett, J. L., P. H. Hemsworth, D. P. Hennessy, T. M. McCallum, and E. A. Newman. 1994. The effects of modifying the amount of human contact on the behavioural, physiological and production responses of laying hens. Appl. Anim. Behav. Sci. 41:87-100. doi:10.1016/0168-1591(94)90054-X.

Barnett, J. L., P. H. Hemsworth, C. G. Winfield, and C. Hansen. 1986. Effects of social environment on welfare status and sexual behaviour of female pigs. I. Effects of group size. Appl. Anim. Behav. Sci. 16:249-257. doi:10.1016/0168-1591(86)90117-6.

Bench, C. J., F. C. Rioja-Lang, S. M. Hayne, and H. W. Gonyou. 2013a. Group gestation housing with individual feeding-I: How feeding regime, resource allocation, and genetic factors affect sow welfare. Livest. Sci. 152:208-217. doi:10.1016/j.livsci.2012.12.021.

Bench, C. J., F. C. Rioja-Lang, S. M. Hayne, and H. W. Gonyou. 2013b. Group gestation housing with individual feeding-II: How space allowance, group size and composition, and flooring affect sow welfare. Livest. Sci. 152:218-227. doi:10.1016/j.livsci.2012.12.020.
Benus, R. F., S. Dendaas, J. M. Koolhaas, and G. A. Vanoortmerssen 1990. Routine formation and flexibility in social and non-social behavior of aggressive and non-aggressive male mice. Behav, 112: 176-193.

Bergeron, R., J. Bolduc, Y. Ramonet, M. C. Meunier-Salaün, and S. Robert. 2000. Feeding motivation and stereotypies in pregnant sows fed increasing levels of fiber and/or food. Appl. Anim. Behav. Sci. 70:27-40. doi:10.1016/S0168-1591(00)00142-8.

Bergeron, R., and H. W. Gonyou. 1997. Effects of increasing energy intake and foraging behaviours on the development of stereotypies in pregnant sows. Appl. Anim. Behav. Sci. 53:259-270. doi:10.1016/S0168-1591(96)01169-0.

Borberg, C., and S. Hoy. 2008. Mixing of sows with or without the presence of a boar. Livest. Sci. 125:314-317. doi:10.1016/j. livsci.2009.04.008.

Boyle, L. A., F. C. Leonard, P. B. Lynch, and P. Brophy. 2002. Effect of gestation housing on behaviour and skin lesions of sows in farrowing crates. Appl. Anim. Behav. Sci. 76:119 134. doi:10.1016/S0168-1591(01)00211-8.

Broom, D. M. 1983. Stereotypes as animal welfare indicators. In: D. Smidt, editor, Indicators relevant to farm animal welfare. Kluwer Academic Publishers, Brussels, The Netherlands. p. 81-87.

Broom, D. M., M. T. Mendl, and A. J. Zanella. 1995. A comparison of the welfare of sows in different housing conditions. Anim. Sci. 61:369-385.

Brouns, F., and S. A. Edwards. 1994. Social rank and feeding behaviour of group-housed sows fed competitively or ad-libitum. App. Anim. Behav. Sci. 39:225-235.

Brouns, F., S. A. Edwards, and P. R. English. 1994. Effect of dietary fiber and feeding system on activity and oral behaviour of group housed gilts. Appl. Anim. Behav. Sci. 39:215-223. doi:10.1016/0168-1591(94)90157-0.

Brouns, F., S. A. Edwards, and P. R. English. 1995. Influence of fibrous feed ingredients on voluntary intake of dry sows. Anim. Feed Sci. Technol. 54:301-313. doi:10.1016/0377-8401(95)00767-H.

Chapinal, N., J. L. Ruiz de la Torre, A. Cerisuelo, J. Gasa, M. D. Baucells, J. Coma, A. Vidal, and X. Manteca. 2010. Evaluation of welfare and productivity in pregnant sows kept in stalls or in 2 different group housing systems. J. Vet. Behav. 5:82-93. doi:10.1016/j.jveb.2009.09.046.

Danielsen, V., and E. M. Vestergaard. 2001. Dietary fiber for pregnant sows: Effect on performance and behaviour. Anim. Feed Sci. Technol. 90:71-80. doi:10.1016/S0377-8401(01)00197-3.

de Jong, I. C., S. Van Voorst, D. A. Ehlhardt, and H. J. Blokhuis. 2002. Effects of restricted feeding on physiological stress parameters in growing broiler breeders. Br. Poult. Sci. 43(2):157-168. doi:10.1080/00071660120121355.

de Leeuw, J. A., J. E. Bolhuis, G. Bosch, and W. J. J. Gerrits. 2008. Effects of dietary fibre on behaviour and satiety in pigs. Proc. Nutr. Soc. 67:334-342. doi:10.1017/S002966510800863X.

de Leeuw, J. A., and E. D. Ekkel. 2004. Effects of feeding level and the presence of a foraging substrate on the behaviour and stress physiological response of individually housed gilts. Appl. Anim. Behav. Sci. 86:15-25. doi:10.1016/j.applanim.2003.12.004.

de Leeuw, J. A., A. W. Jongbloed, and M. W. A. Verstegen. 2004. Dietary fiber stabilizes blood glucose and insulin levels and reduces physical activity in sows (Sus scrofa). J. Nutr. 134:1481-1486.

de Leeuw, J. A., J. J. Zonderland, H. Altena, H. A. M. Spoolder, A. W. Jongbloed, and M. W. A. Verstegen. 2005. Effects of levels and sources of dietary fermentable non-starch polysaccharides on blood glucose stability and behaviour of grouphoused pregnant gilts. Appl. Anim. Behav. Sci. 94:15-29. doi:10.1016/j.applanim.2005.02.006.

D'Eath, R. B. 2004. Consistency of aggressive temperament in domestic pigs: The effects of social experience and social disruption. Aggress. Behav. 30:435-448. doi:10.1002/ab.20077. 
D'Eath, R. B. 2005. Socialising piglets before weaning improves social hierarchy formation when pigs are mixed post-weaning. Appl. Anim. Behav. Sci. 93:199-211. doi:10.1016/j.applanim.2004.11.019.

D'Eath, R. B., and L. J. Keeling. 2003. Social discrimination and aggression by laying hens in large groups: From peck orders to social tolerance. Appl. Anim. Behav. Sci. 84:197-212. doi:10.1016/j.applanim.2003.08.010.

D'Eath, R. B., R. Roehe, S. P. Turner, S. H. Ison, S. H. Farish, M. C. Jack, and A. B. Lawrence. 2009. Genetics of animal temperament: Aggressive behaviour at mixing is genetically associated with the response to handling in pigs. Animal 3:1544-1554. doi:10.1017/S1751731109990528.

Department for Environment, Food and Rural Affairs. 2003. Code of Recommendations for the welfare of livestock: pigs. Defra publications, London.

Docking, C. M., R. M. Kay, J. E. L. Day, and H. L. Chamberlain. 2001. The effect of stocking density, group size and boar presence on the behaviour, aggression and skin damage of sows mixed in a specialized mixing pen at weaning. In: Proc. Brit. Soc. Anim. Sci., Scarborough, UK. p. 46. (Abst).

Durrell, J. L., V. E. Beattie, I. A. Sneddon, and D. Kilpatrick. 2003. Premixing as a technique for facilitating subgroup formation and reducing sow aggression in large dynamic groups. Appl. Anim. Behav. Sci. 84:89-99. doi:10.1016/j.applanim.2003.06.001.

Durrell, J. L., I. A. Sneddon, and V. E. Beattie. 1997. Effects of enrichment and floor type on behaviour of cubicle loose-housed dry sows. Anim. Welf. 6:297-308.

Durrell, J. L., I. A. Sneddon, V. E. Beattie, and D. J. Kilpatrick. 2002. Sow behaviour and welfare in voluntary cubicle pens (small static groups) and split-yard systems (large dynamic groups). Anim. Sci. 75:67-74.

Edwards, S. A. 1992. Scientific perspectives on loose housing systems for dry sows. Pig Vet. J. 28:40-51.

Edwards, S. A., S. Mauchline, and A. H. Stewart. 1993. Designing pens to minimise aggression when sows are mixed. Farm Build. Prog. 113:20-23.

Erhard, H. W., and M. Mendl. 1997. Measuring aggressiveness in growing pigs in a resident-intruder situation. Appl. Anim. Behav. Sci. 54:123-136. doi:10.1016/S0168-1591(97)00069-5.

Erhard, H. W., M. Mendl, and D. Ashley. 1997. Individual aggressiveness of pigs can be measured and used to reduce aggression after mixing. Appl. Anim. Behav. Sci. 54:137-151. doi:10.1016/S0168-1591(97)00068-3.

Fisker, B. N. 1995. Strategy for transfer of group-housed gestating sows. Pig Research Centre. http://vsp.lf.dk/Publikationer/ Kilder/lu_medd/medd/311.aspx. (In Danish.) (Accessed 2 September 2014.)

Fisker, B. N. 1999. Feed with 60 \% 'Pulpetter' (dried sugar beet pulp) for gestating sows housed in stable groups. Pig Research Centre. http://vsp.lf.dk/Publikationer/Kilder/lu_medd/ medd/444.aspx. (In Danish) Accessed 2 September 2014.)

Fraile, I. G., B. S. McEwen, and D. W. Pfaff. 1987. Progesterone inhibition of aggressive behaviors in hamsters. Physiol. Behav. 39:225-229. doi:10.1016/0031-9384(87)90013-8.

Fraser, D. 2008. Understanding animal welfare: The science in its cultural context. Wiley-Blackwell, West Sussex, UK.

Gabor, T. M., E. C. Hellgren, R. A. Van den Bussche, and N. J. Silvy. 1999. Demography, sociospatial behaviour and genetics of feral pigs (Sus scrofa) in a semi-arid environment. J. Zool., 247, 311-322.

Geverink, N. A., B. Ampe, E. Struelens, and F. A. M. Tuyttens. 2008. On-farm welfare evaluation of group-housed sows. In:L. Boyle, N. O'Connell and A. Hanlon Proc. 42nd Congr. Intl. Soc. Appl. Ethol., Dublin, Ireland. p. 8. (Abst).
Geverink, N. A., and F. A. M. Tuyttens. 2007. On-farm evaluation of group-housing for sows. In:F. Galindo and L. Alvarez Proc. 41st Int. Congr. Intl. Soc. Appl. Ethol., Merida, Mexico. p. 201. (Abst).

Gonyou, H. W. 2001. The social behaviour of pigs. In: L. J. Keeling and H. W. Gonyou, editors, Social behaviour of farm animals. CABI, Oxfordshire, UK. p. 147-176.

Gonyou, H. W. 2005. Experiences with alternative methods of sow housing. J. Am. Vet. Med. Assoc. 226:1336-1339. doi:10.2460/javma.2005.226.1336.

Gonyou, H. W., P. H. Hemsworth, and J. L. Barnett. 1986. Effects of frequent interactions with humans on growing pigs. Appl. Anim. Behav. Sci. 16:269-278. doi:10.1016/0168-1591(86)90119-X.

Heinonen, M., O. Peltoniemi, and A. Valros. 2013. Impact of lameness and claw lesions in sows on welfare, health and production. Livest. Sci. 156:2-9. doi:10.1016/j.livsci.2013.06.002.

Hemsworth, P. H., J. L. Barnett, and G. J. Coleman. 2009. The integration of human-animal relations into animal welfare monitoring schemes. Anim. Welf. 18:335-345.

Hemsworth, P. H., J. L. Barnett, G. J. Coleman, and C. Hansen. 1989. A study of the relationships between the attitudinal and behavioural profiles of stockpersons and the level of fear of humans and reproductive performance of commercial pigs. Appl. Anim. Behav. Sci. 23:301-314. doi:10.1016/0168-1591(89)90099-3.

Hemsworth, P. H., J. L. Barnett, and C. Hansen. 1986b. The influence of handling by humans on the behaviour, reproduction and corticosteroids of male and female pigs. Appl. Anim. Behav. Sci. 15:303-314. doi:10.1016/0168-1591(86)90123-1.

Hemsworth, P. H., J. L. Barnett, and C. Hansen. 1981b. The influence of handling by humans on the behaviour, growth and corticosteroids in the juvenile female pig. Horm. Behav. 15:396-403. doi:10.1016/0018-506X(81)90004-0.

Hemsworth, P. H., J. L. Barnett, and C. Hansen. 1987. The influence of inconsistent handling on the behaviour, growth and corticosteroids of young pigs. Appl. Anim. Behav. Sci. 17:245-252. doi:10.1016/0168-1591(87)90149-3.

Hemsworth, P. H., J. L. Barnett, C. Hansen, and C. G. Winfield. 1986a. Effects of social environment on welfare status and sexual behaviour of female pigs. II. Effects of space allowance. Appl. Anim. Behav. Sci. 16:259-267. doi:10.1016/0168-1591(86)90118-8.

Hemsworth, P. H., A. Brand, and P. J. Willems. 1981b. The behavioural response of sows to the presence of human beings and their productivity. Livest. Prod. Sci. 8:67-74. doi:10.1016/0301-6226(81)90031-2.

Hemsworth, P. H., and G. J. Coleman. 2011. Human-livestock interactions: The stockperson and the productivity and welfare of farmed animals, 2nd ed. CAB International, Oxon UK.

Hemsworth, P. H., G. J. Coleman, and J. L. Barnett. 1994. Improving the attitude and behaviour of stockpersons towards pigs and the consequences on the behaviour and reproductive performance of commercial pigs. Appl. Anim. Behav. Sci. 39:349-362. doi:10.1016/0168-1591(94)90168-6.

Hemsworth, P. H., M. Rice, J. Nash, K. Giri, K. L. Butler, A. J. Tilbrook, and R. S. Morrison. 2013. Effects of group size and floor space allowance on grouped sows: Aggression, stress, skin injuries and reproductive performance. J. Anim. Sci. 91:4953-4964. doi:10.2527/jas.2012-5807.

Hillmann, E., F. von Hollen, B. Bunger, D. Todt, and L. Schrader. 2003. Farrowing conditions affect the reactions of piglets towards novel environment and social confrontation at weaning. Appl. Anim. Behav. Sci. 81:99-109. doi:10.1016/S0168-1591(02)00254-X.

Hodgkiss, N. J., J. C. Eddison, P. H. Brooks, and P. Bugg. 1998. Assessment of the injuries sustained by pregnant sows housed in groups using electronic feeders. Vet. Rec. 143:604-607. doi:10.1136/vr.143.22.604. 
Hsu, Y. Y., R. L. Earley, and L. L. Wolf. 2006. Modulation of aggressive behaviour by fighting experience: Mechanisms and contest outcomes. Biol. Rev. Camb. Philos. Soc. 81:33-74. doi: $10.1017 / \mathrm{S} 146479310500686 \mathrm{X}$.

Hsu, Y. Y., and L. L. Wolf. 2001. The winner and loser effect: What fighting behaviours are influenced? Anim. Behav. 61:777-786. doi:10.1006/anbe.2000.1650.

Hunter, E. J., D. M. Broom, S. A. Edwards, and R. M. Sibly. 1988. Social hierarchy and feeder access in a group of 20 sows using a computer controlled feeder. Anim. Prod. 47:139-148. doi: $10.1017 /$ S0003356100037144.

Hutson, G. D. 1991. A note on hunger in the pig: Sows on restricted rations will sustain an energy deficit to gain additional food. Anim. Prod. 52:233-235. doi:10.1017/S0003356100005882.

Jansen, J., R. N. Kirkwood, A. J. Zanella, and R. J. Templeman. 2007. Influence of gestation housing on sow behaviour and fertility. J. Swine Health Prod. 15:132-136.

Jensen, K. H., L. S. Sørensen, D. Bertelsen, A. R. Pedersen, E. Jørgensen, N. P. Nielsen, and K. S. Vestergaard. 2000. Management factors affecting activity and aggression in dynamic group housing systems with electronic sow feeding: A field trial. J. Anim. Sci. 71:535-545.

Jensen, M. B., L. J. Pedersen, P. K. Theil, C. C. Yde, and K. E. Bach Knudsen. 2012. Feeding motivation and plasma metabolites in pregnant sows fed diets rich in dietary fiber either once or twice daily. J. Anim. Sci. 90:1910-1919. doi:10.2527/jas.2010-3289.

Jensen, P., and J. Yngvesson. 1998. Aggression between unacquainted pigs - Sequential assessment and effects of familiarity and weight. Appl. Anim. Behav. Sci. 58:49-61. doi:10.1016/S0168-1591(97)00097-X.

Karlen, G. A. M., P. H. Hemsworth, H. W. Gonyou, E. Fabrega, A. D. Strom, and R. J. Smits. 2007. The welfare of gestating sows in conventional stalls and large groups on deep litter. App. Anim. Behav. Sci, 105:87-101.

Kemp, B., N. M. Soede, and P. Langendijk. 2005. Effects of boar contact and housing condition on estrus expression in sows. Theriogenology 63:643-656. doi:10.1016/j.theriogenology.2004.09.038.

Kennedy, M. J., and D. M. Broom. 1994. A method of mixing gilts and sows which reduces aggression experienced by gilts. Proc. 28th Int. Congr. Intl. Soc. Appl. Ethol., Foulum, Denmark. p. 157. (Abst).

Kennedy, M. J., and D. M. Broom. 1996. Factors modulating aggression received by pigs mixed individually into groups. In: I. J. H. Duncan, T. M. Widowski, and D. B. Haley Proc. 30th Int. Congr. Intl. Soc. Appl. Ethol., Ontario, Canada, p. 52. (Abst).

Kirchner, J., G. Manteuffel, and L. Schrader. 2012. Individual calling to the feeding station can reduce agonistic interactions and lesions in group housed sows. J. Anim. Sci. 90:50135020. doi:10.2527/jas.2011-4478.

Knox, R., J. Salak-Johnson, M. Hopgood, L. Greiner, and J. Connor. 2014. Effect of day of mixing gestating sows on measures of reproductive performance and animal welfare. J. Anim. Sci. 92:1698-1707. doi:10.2527/jas.2013-6432.

Kohlert, J. G., and R. L. Meisel. 2001. Inhibition of aggression by progesterone and its metabolites in female Syrian hamsters. Aggress. Behav. 27:372-381. doi:10.1002/ab.1022.

Krause, M., C. E. Vant Klooster, R. G. Bure, J. H. M. Metz, and H. H. Sambraus. 1997. The influence of sequential and simultaneous feeding and the availability of straw on the behaviour of gilts in group housing. Neth. J. Agric. Sci. 45:33-48.

Kudryavtseva, N. N., N. P. Bondar, and D. F. Avgustinovich. 2004. Effects of repeated experience of aggression on the aggressive motivation and development of anxiety in male mice. Neurosci. Behav. Physiol. 34:721-730. doi:10.1023/ B:NEAB.0000036013.11705.25.
Langendijk, P., and O. Peltoniemi. 2013. How does nutrition influence luteal function and early embryo survival? In: $\mathrm{H}$. Rodriguez-Martinez. N. Soede, and W. L. Flowers Control of pig reproduction IX: Proc. Int. Conf. Pig. Reprod., Osztyn, Poland. p. 49. (Abst).

Langendijk, P., N. M. Soede, and B. Kemp. 2000. Effects of boar contact and housing conditions on estrus expression in weaned sows. J. Anim. Sci. 78:871-878.

Lawrence, A. B., M. C. Appleby, and H. A. MacLeod. 1989. Measuring hunger in the pig using operant conditioning: The effect of dietary bulk. Anim. Prod. 48:213-220. doi:10.1017/S0003356100003925.

Lawrence, A. B., and E. M. C. Terlouw. 1993. A review of behavioural factors involved in the development and continued performance of stereotypic behaviours in pigs. J. Anim. Sci. 71:2815-2825.

Leeb, B., C. Leeb, J. Troxler, and M. Schuh. 2001. Skin lesions and callosities in group-housed pregnant sows: Animal-related welfare indicators. Acta Agric. Scand. Sect A. 51:82-87.

Lehner, S. R., C. Rutte, and M. Taborsky. 2011. Rats benefit from winner and loser effects. Ethology. 117:949-960.

Li, Y. Z., and H. W. Gonyou. 2013. Comparison of management options for sows kept in pens with electronic feeding stations. Can. J. Anim. Sci. 93:445-452. doi:10.4141/cjas2013-044.

Li, Y. Z., and L. J. Johnston. 2009. Behaviour and performance of pigs previously housed in large groups. J. Anim. Sci. 87:1472-1478. doi:10.2527/jas.2008-1202.

Li, Y. Z., L. H. Wang, and L. J. Johnston. 2012. Sorting by parity to reduce aggression toward first parity sows in group-gestation housing systems. J. Anim. Sci. 90:4514-4522. doi:10.2527/ jas.2011-4869.

Lindberg, A. C. 2001. Group life. In: L. J. Keeling and H. W. Gonyou, editors, Social behaviour in farm animals. CABI, Oxfordshire, UK. p. 37-58.

Løvendahl, P., L. H. Damgaard, B. L. Nielsen, K. Thodberg, G. Su, and L. Rydhmer. 2005. Aggressive behaviour of sows at mixing and maternal behaviour are heritable and genetically correlated traits. Livest. Prod. Sci. 93:73-85. doi:10.1016/j. livprodsci.2004.11.008.

Marchant-Forde, J. N. 2009. Welfare of dry sows. In: J. N. Marchant-Forde, editor, The welfare of pigs. Springer, New York, NY. p. 95-139.

Marchant-Forde, J. N., and R. M. Marchant-Forde. 2005. Minimizing inter-pig aggression during mixing. Pig News Info. $26: 63 \mathrm{~N}-71 \mathrm{~N}$.

Mason, G. J., and N. R. Latham. 2004. Can't stop, won't stop: Is stereotypy a reliable animal welfare indicator? Anim. Welf. 13:S57-S69.

Matthews, L. R., and P. H. Hemsworth. 2012. Drivers of change: Law, international markets, and policy. Anim. Front. 2:40-45. doi:10.2527/af.2012-0047.

Mendl, M., and J. M. Deag. 1995. How useful are the concepts of alternative strategy and coping strategy in applied studies of social behavior. App. Anim. Behav. Sci. 44:119-137.

Mendl, M., A. J. Zanella, and D. M. Broom. 1992. Physiological and reproductive correlates of behavioural strategies in female domestic pigs. Anim. Behav. 44:1107-1121. doi:10.1016/S0003-3472(05)80323-9.

Meunier-Salaün, M. C., S. A. Edwards, and S. Robert. 2001. Effect of dietary fiber on the behaviour and health of the restricted sow. Anim. Feed Sci. Technol. 90:53-69. doi:10.1016/ S0377-8401(01)00196-1.

Moore, A. S., H. W. Gonyou, and A. W. Ghent. 1993. Integration of newly introduced and resident sows following grouping. Appl. Anim. Behav. Sci. 38:257-267. doi:10.1016/0168-1591(93)90024-J.

Mount, N. C., and M. F. Seabrook. 1993. A study of aggression when group housed sows are mixed. Appl. Anim. Behav. Sci. 36:377-383. doi:10.1016/0168-1591(93)90134-B. 
Muráni, E., S. Ponsuksii, R. B. D'Eath, S. P. Turner, E. Kurt, G Evans, L. Thölking, R. Klont, A. Foury, P. Mormède, and K. Wimmers. 2010. Association of HPA axis related genetic variation with stress reactivity and aggressive behaviour in pigs. BMC Genet. 11:74. doi:10.1186/1471-2156-11-74.

Newberry, R. C., M. Špinka, and S. Cloutier. 2000. Early social experience of piglets affects rate of conflict resolution with strangers after weaning. In:A. Ramos, L. C. Pinheiro Machade and M. J. Hötzel Proc. 34th Int. Congr. Intl. Soc. Appl. Ethol., Florianópolis, Brazil. p. 67. (Abst).

Nicholson, R. I., J. J. McGlone, and L. N. Reid. 1993. Quantification of stress in sows: Comparison of individual housing versus social penning. J. Anim. Sci. 71(Suppl. 1):112 (Abstr.).

Nicol, C. J., G. Caplen, P. Statham, and W. J. Browne. 2011. Decisions about foraging and risk trade-offs in chickens are associated with individual somatic response profiles. Anim. Behav. 82:255-262. doi:10.1016/j.anbehav.2011.04.022.

Nielsen, B. L., A. B. Lawrence, and C. T. Whittemore. 1995. Effect of group size on feeding behaviour, social behaviour, and performance of growing pigs using single-space feeders. Livest. Prod. Sci. 44:73-85. doi:10.1016/0301-6226(95)00060-X.

Nielsen, N.-P. 1999. Time of grouping of sows housed in dynamic groups. Pig Research Centre. http://vsp.lf.dk/Publikationer/ Kilder/lu_medd/medd/451.aspx. (In Danish.) (Accessed 2 September 2014.)

O'Connell, N. E. 2007. Influence of access to grass silage on the welfare of sows introduced to a large dynamic group. Appl. Anim. Behav. Sci. 107:45-57. doi:10.1016/j.applanim.2006.09.020.

Olsson, A. C., M. Andersson, J. Botermans, D. Rantzer, and J. Svendsen. 2011. Animal interaction and response to electronic sow feeding (ESF) in 3 different herds and effects of function settings to increase capacity. Livest. Sci. 137:268-272. doi: $10.1016 /$ j.livsci.2010.10.014

Olsson, A. C., and O. V. Samuelsson. 1993. Grouping studies of lactating and newly weaned sows. In: E. Collins and C. Boom Proc. 4th Int. Symp. Am. Soc. Agri. Eng. Livest. Environ, Coventry, UK. 475-482.

Olsson, A. C., J. Svendsen, and D. Reese. 1994. Housing of gestating sows in long narrow pens with liquid feeding: Function studies and grouping routines in five sow pools. Swed. J. Agric. Res. 24:131-141.

Olsson, I. A. S., F. H. de Jonge, T. Schuurman, and F. A. Helmond. 1999. Poor rearing conditions and social stress in pigs: Repeated social challenge and the effect on behavioural and physiological responses to stressors. Behav. Processes 46:201-215. doi:10.1016/S0376-6357(99)00036-4.

Pedersen, L. J., T. Heiskanen, and B. I. Damm. 2003. Sexual motivation in relation to social rank in pair-housed sows. Anim. Reprod. Sci. 75:39-53. doi:10.1016/S0378-4320(02)00208-7.

Pedersen, L. J., T. Rojkittikhun, S. Einarsson, and L. E. Edqvist. 1993. Postweaning grouped sows: Effects of aggression on hormonal patterns and estrus behaviour. Appl. Anim. Behav. Sci. 38:25-39. doi:10.1016/0168-1591(93)90039-R.

Potegal, M. 1979. The reinforcing value of several types of aggressive behavior:Areview. Aggressive Behav. 5:353-373. doi:10.1002/10982337(1979)5:4<353::AID-AB2480050404>3.0.CO;2-7

Puppe, B. 1998. Effects of familiarity and relatedness on agonistic pair relationships in newly mixed domestic pigs. Appl. Anim. Behav. Sci. 58:233-239. doi:10.1016/S0168-1591(98)00107-5.

Ramonet, Y., J. Bolduc, R. Bergeron, S. Robert, and M. C. MeunierSalaün. 2000. Feeding motivation in pregnant sows: Effects of fibrous diets in an operant conditioning procedure. Appl. Anim. Behav. Sci. 66:21-29. doi:10.1016/S0168-1591(99)00077-5.
Ramonet, Y., J. Bolduc, S. Robert, R. Bergeron, and M. C. MeunierSalaün. 1998. Feeding motivation and stereotypies in pregnant sows fed increasing levels of fiber and/or food. In: I. Veissier and A. Boissy Proc. 32nd Congr. Intl. Soc. Appl. Ethol.., Clermont-Ferrand, France. p. 181. (Abst).

Rasmussen, H. 2012. Socialising gilts to cope as young sows in group housing. In: S. Waiblinger, C. Winckler and A. Gutmann Proc. 46th Congr. Intl. Soc. Appl. Ethol., Vienna, Austria. p. 115. (Abst).

Rault, J.-L., R. M. Morrison, C. Hansen, and P. H. Hemsworth. 2014. Effects of group housing after weaning on sow welfare and sexual behavior. J. Anim. Sci. 92:5683-5692. doi: $10.2527 /$ jas.2014-8238.

Réale, D., and N. J. Dingemanse. 2010. Personality and individual social specialisation. In: T. Székely, A. J. Moore and J. Komdeur, editors, Social Behaviour: Genes, Ecology and Evolution. Cambridge University Press, Cambridge, UK. p. 417-441.

Remience, V., J. Wavreille, B. Canart, M. C. Meunier-Salaün, A Prunier, N. Bartiaux-Thill, B. Nicks, and M. Vandenheede. 2008. Effects of space allowance on the welfare of dry sows kept in dynamic groups and fed with electronic sow feeder. Appl. Anim. Behav. Sci. 112:284-296. doi:10.1016/j.applanim.2007.07.006.

Robert, S., R. Bergeron, C. Farmer, and M. C. Meunier-Salaun. 2002. Does the number of daily meals affect feeding motivation and behaviour of gilts fed high-fiber diets? Appl. Anim. Behav. Sci. 76:105-117. doi:10.1016/S0168-1591(02)00003-5.

Robert, S., J. J. Matte, C. Farmer, C. L. Girard, and G. P. Martineau. 1993. High-fiber diets for sows: Effects on stereotypies and adjunctive drinking. Appl. Anim. Behav. Sci. 37:297-309. doi:10.1016/0168-1591(93)90119-A.

Robert, S., J. Rushen, and C. Farmer. 1997. Both energy content and bulk of food affect stereotypic, heart rate and feeding motivation of female pigs. Appl. Anim. Behav. Sci. 54:161171. doi:10.1016/S0168-1591(97)00067-1.

Rodenburg, B., and P. Koene. 2007. The impact of group size on damaging behaviours, aggression, fear and stress in farm animals. Appl. Anim. Behav. Sci. 103:205-214. doi:10.1016/j. applanim.2006.05.024.

Rodríguez-Estévez, V., M. Sánchez-Rodríguez, A. G. GómezCastro, and S. A. Edwards. 2010. Group sizes and resting locations of free range pigs when grazing in a natural environment. Appl. Anim. Behav. Sci. 127:28-36. doi:10.1016/j. applanim.2010.08.010.

Salak-Johnson, J. L., A. E. DeDecker, M. J. Horsman, and S. L. Rodriguez-Zas. 2012. Space allowance for gestation sows in pen: Behavior and immunity. J. Anim. Sci. 90:3232-3242. doi: 10.2527/jas.2011-4531.

Salak-Johnson, J. L., S. R. Niekamp, S. L. Rodriguez-Zas, M. Ellis, and S. E. Curtis. 2007. Space allowance for dry, pregnant sows in pens: Body condition, skin lesions and performance. J. Anim. Sci. 85:1758-1769. doi:10.2527/jas.2006-510.

Samarakone, T. S., and H. W. Gonyou. 2009. Domestic pigs alter their social strategy in response to social group size. Appl. Anim. Behav. Sci. 121:8-15. doi:10.1016/j.applanim.2009.08.006.

Schneider, J. D., M. D. Tokach, S. S. Dritz, J. L. Nelssen, J. M. DeRouchey, and R. D. Goodband. 2007. Effects of feeding schedule on body condition, aggressiveness, and reproductive failure in group-housed sows. J. Anim. Sci. 85:34623469. doi:10.2527/jas.2007-0345.

Scott, K., G. P. Binnendijk, S. A. Edwards, J. H. Guy, M. C. Kiezebrink, and H. M. Vermeer. 2009. Preliminary evaluation of a prototype welfare monitoring system for sows and piglets (Welfare Quality ${ }^{\circledR}$ project). Anim. Welf. 18:441-449.

Séguin, M. J., R. M. Friendship, R. N. Kirkwood, A. J. Zanella, and T. M. Widowski. 2006. Effects of boar presence on agonistic behaviour, shoulder scratches, and stress response of bred sows at mixing. J. Anim. Sci. 84:1227-1237. 
Souza da Silva, C., J. J. G. C. van den Borne, W. J. J. Gerrits, B. Kemp, and J. E. Bolhuis. 2012. Effects of dietary fibers with different physiochemical properties on feeding motivation in adult female pigs. Physiol. Behav. 107:218-230. doi:10.1016/j.physbeh.2012.07.001.

Spoolder, H. A. M., J. A. Burbridge, S. A. Edwards, A. B. Lawrence, and P. H. Simmins. 1997. Effect of food level on performance and behaviour of sows in a dynamic group-housing systems with electronic feeding. Anim. Sci. 65:473-482. doi:10.1017/ S1357729800008675.

Spoolder, H. A. M., J. A. Burbidge, S. A. Edwards, P. H. Simmins, and A. L. Lawrence. 1995. Provision of straw as a foraging substrate reduces the development of excessive chain and bar manipulation in food restricted sows. Appl. Anim. Behav. Sci. 43:249-262. doi:10.1016/0168-1591(95)00566-B.

Spoolder, H. A. M., M. J. Geudeke, C. M. C. Van der PeetSchwering, and N. M. Soede. 2009. Group housing of sows in early pregnancy: A review of success and risk factors. Livest. Sci. 125:1-14. doi:10.1016/j.livsci.2009.03.009.

Stevens, B., G. M. Karlen, R. Morrison, H. W. Gonyou, K. L. Butler, K. J. Kerswell, and P. J. Hemsworth. 2015. Effects of stage of gestation at mixing on aggression, injuries and stress in sows. Appl. Anim. Behav. Sci. 165:40-46. doi:10.1016/j. applanim.2015.02.002.

Stewart, C. L., N. E. O'Connell, and L. Boyle. 2008. Influence of access to straw provided in racks on the welfare of sows in large dynamic groups. Appl. Anim. Behav. Sci. 112:235-247. doi:10.1016/j.applanim.2007.09.006.

Strawford, M. L., Y. Z. Li, and H. W. Gonyou. 2008. The effect of management strategies and parity on the behaviour and physiology of gestating sows housed in an electronic sow feeding system. Can. J. Anim. Sci. 88:559-567. doi:10.4141/CJAS07114.

Stricklin, W. R. 2001. The evolution and domestication of social behaviour. In: L. J. Keeling and H. W. Gonyou, editors, Social behaviour in farm animals. CAB International, Oxon, UK. p. 83-110.

Stukenborg, A., I. Traulsen, E. Stamer, B. Puppe, U. Presuhn, and J. Krieter. 2012. Heritabilities of agonistic behavioural traits in pigs and their relationships within and between different age groups. Livest. Sci. 149:25-32. doi:10.1016/j.livsci.2012.06.020.

Taylor, I. A., J. L. Barnett, and G. M. Cronin. 1997. Optimum group size for pigs. In: R. W. Bottcher and S. J. Hoff Proc. 5th. Int. Symp. Am. Soc. Agri. Eng. Livest. Environ., MI. p. 965-971.

Terlouw, E. M., A. B. Lawrence, and A. W. Illius. 1991. Influences of feeding level and physical restriction on development of stereotypies in sows. Anim. Behav. 42:981-991. doi:10.1016/ S0003-3472(05)80151-4.

Toscano, M. J., D. C. Lay, B. A. Craig, and E. A. Pajor. 2007. Assessing the adaptation of swine to fifty-seven hours of feed deprivation in terms of behavioral and physiological responses. J. Anim. Sci. 85(2):441-451. doi:10.2527/jas.2006-316.

Turner, S. P., and S. A. Edwards. 2004. Housing immature domestic pigs in large social groups: Implications for social organisation in a hierarchical society. Appl. Anim. Behav. Sci. 87:239-253. doi:10.1016/j.applanim.2004.01.010.

Turner, S. P., S. A. Edwards, and V. C. Bland. 1999. The influence of drinker allocation and group size on the drinking behaviour, welfare and production of growing pigs. Anim. Sci. 68:617-624.

Turner, S. P., M. Ewen, J. A. Rooke, and S. A. Edwards. 2000. The effect of space allowance on performance, aggression and immune competence of growing pigs housed on straw deeplitter at different group sizes. Livest. Prod. Sci. 66:47-55. doi:10.1016/S0301-6226(00)00159-7.
Turner, S. P., M. J. Farnworth, I. M. S. White, S. Brotherstone, M. Mendl, P. Knap, P. Penny, and A. B. Lawrence. 2006. The accumulation of skin lesions and their use as a predictor of individual aggressiveness in pigs. Appl. Anim. Behav. Sci. 96:245-259. doi:10.1016/j.applanim.2005.06.009.

Turner, S. P., R. Roehe, R. B. D'Eath, S. H. Ison, M. Farish, M. C. Jack, N. Lundeheim, L. Rydhmer, and A. B. Lawrence. 2009. Genetic validation of skin injuries in pigs as an indicator of post-mixing aggressiveness and the relationship with aggression under stable social conditions. J. Anim. Sci. 87:30763082. doi:10.2527/jas.2008-1558.

Turner, S. P., R. Roehe, W. Mekkawy, M. J. Farnworth, P. W. Knap, and A. B. Lawrence. 2008. Bayesian analysis of genetic associations of skin lesions and behavioural traits to identify genetic components of individual aggressiveness in pigs. Behav. Genet. 38:67-75. doi:10.1007/s10519-007-9171-2.

van Putten, G., and R. G. Buré. 1997. Preparing gilts for group housing by increasing their social skills. Appl. Anim. Behav. Sci. 54:173-183. doi:10.1016/S0168-1591(97)00063-4.

van Putten, G., and J. A. van de Burgwal. 1990. Vulva biting in group-housed sows: Preliminary report. Appl. Anim. Behav. Sci. 26:181-186. doi:10.1016/0168-1591(90)90097-W.

Velarde, A. 2007. Agonistic behaviour. In: A. Velarde and R. Reers, editors, On farm monitoring of pig welfare. Wageningen Academic Press, Wageningen, The Netherlands. p. 53-56.

Verdon, M. 2014. Sow aggression in groups: Predicting and implications for sow welfare. PhD Diss. The Animal Welfare Science Centre, The University of Melbourne, Australia.

Virolainen, J. V., O. A. Peltoniemi, C. Munsterhjelm, A. Tast, and S. Einarsson. 2005. Effect of feeding level on progesterone concentration in early pregnant multiparous sows. Anim. Reprod. Sci. 90:117-126. doi:10.1016/j.anireprosci.2005.01.012.

Virolainen, J. V., A. Tast, A. Sorsa, R. J. Love, and O. A. T. Peltoniemi. 2004. Changes in feeding level during early pregnancy affect fertility in gilts. Anim. Reprod. Sci. 80:341-352. doi:10.1016/j.anireprosci.2003.08.005.

Weng, R. C., S. A. Edwards, and P. R. English. 1998. Behaviour, social interactions and lesion score of group-housed sows in relation to floor space allowance. Appl. Anim. Behav. Sci. 59:307-316. doi:10.1016/S0168-1591(97)00143-3.

Wechsler, B. 1995. Coping and coping strategies - a behavioral view. App. Anim. Behav. Sci. 43:123-134.

Whittaker, X., S. A. Edwards, H. A. M. Spoolder, A. B. Lawrence, and S. Corning. 1999. Effects of straw bedding and high fiber diets on the behaviour of floor fed group-housed sows. Appl. Anim. Behav. Sci. 63:25-39. doi:10.1016/S0168-1591(98)00243-3.

Whittaker, X., H. A. M. Spoolder, S. A. Edwards, A. B. Lawrence, and S. Corning. 1998. The influence of dietary fiber and the provision of straw on the development of stereotypic behaviour in food restricted pregnant sows. Appl. Anim. Behav. Sci. 61:89-102. doi:10.1016/S0168-1591(98)00183-X.

Wiegand, R. M., H. W. Gonyou, and S. E. Curtis. 1994. Pen shape and size: Effects on pigs behaviour and performance. Appl. Anim. Behav. Sci. 39:49-61. doi:10.1016/0168-1591(94)90015-9.

Wiepkema, P. R. 1983. On the significance of ethological criteria for the assessment of animal welfare. In: D. Smidt, editor, Indicators relevant to farm animal welfare. Martinus Nijhoff, The Hague, Netherlands. p. 71-79.

Zonderland, J. J., J. A. de Leeuw, C. Nolten, and H. A. M. Spoolder. 2004. Assessing long term behavioural effects of feeding motivation in group-housed pregnant sows; What, when and how to observe. Appl. Anim. Behav. Sci. 87:15-30. doi:10.1016/j. applanim.2003.12.009.

Zurbrigg, K., and T. Blackwell. 2006. Injuries, lameness and cleanliness of sows in four-group-housing gestation facilities in Ontario. J. Swine Health Prod. 14:202-206. 
